\title{
Natural Gas Pricing Reform in China: Getting Closer to a Market System?
}

\author{
Sergey Paltsev ${ }^{\mathrm{a},{ }^{*}}$ and Danwei Zhang ${ }^{\mathrm{a},{ }^{*}}$
}

${ }^{a}$ MIT Joint Program on the Science and Policy of Global Change, Massachusetts Institute of Technology, 77 Massachusetts Ave., E19-411, Cambridge, MA 02139, USA

*Corresponding Authors.

E-mail addresses: paltsev@ mit.edu (S.Paltsev), zhangdw@ mit.edu (D. Zhang).

\begin{abstract}
Recent policy in China targets an increase in the contribution of natural gas to the nation's energy supply. Historically, China's natural gas prices have been highly regulated with a goal to protect consumers. The old pricing regime failed to provide enough incentives for natural gas suppliers, which often resulted in natural gas shortage. A new gas pricing reform was tested in Guangdong and Guangxi provinces in 2011, and introduced nationwide in 2013. The reform is aimed at creating a more market-based pricing mechanism. We show that a substantial progress toward a better predictability and transparency of prices has been made. The prices are now more connected with the international fuel oil and liquid petroleum gas prices. The government's approach for a temporary two-tier pricing when some volumes are still traded at old prices reduced a potential opposition during the new regime implementation. Some limitations of the natural gas pricing remain as it created biased incentives for producers and favors large natural gas suppliers. The pricing reform at its current stage falls short of establishing a complete market mechanism driven by an interaction of supply and demand of natural gas in China.
\end{abstract}

Keywords: China, natural gas, prices, reform, energy policy. 


\section{INTRODUCTION}

One of the recent key energy policy objectives in China is increasing the contribution of natural gas in the energy mix (NEA, 2014). This objective is driven primarily by lower emissions of carbon dioxide and air pollutants from natural gas in comparison to coal, which is currently China's main energy source. Natural gas in 2013 accounted for approximately $6 \%$ of the total China's energy consumption (NBS, 2014a) ${ }^{1}$. According to China's National Energy Strategy Action Plan released in 2014, the natural gas share in China's primary energy supply is planned to exceed $10 \%$ by 2020 (NEA, 2014). To achieve this substantial increase, China has reformed its natural gas pricing, as highly-regulated and non-transparent prices have been limiting factors for expanding the supply of natural gas.

The goal of this paper is to assess the recent developments in China's natural gas price reform, which was introduced nationwide in 2013. Before the reform, the wholesale gas prices were set on a cost-plus approach and price differentials were distinguished by end users, with residential users paying lower prices than industrial users (IEA, 2012). Such a cost-plus approach was developed when China's uses were covered by domestic sources of natural gas and the existing suppliers were compensated for the cost of production. After 2010, China's volumes of imported natural gas were increasing due to construction of pipelines from Central Asia and LNG terminals on the East coast. With regulated domestic price at low levels, importers of natural gas were losing money as the contract prices for China's imported natural gas were higher than the regulated prices. The old pricing approach also failed to provide incentives for an expansion of domestic natural gas supply, both conventional and unconventional ${ }^{2}$. At the same

\footnotetext{
${ }^{1}$ Energy statistics is organized differently in different agencies. For example, International Energy Agency (IEA) also counts traditional biomass use in the total energy use in China (IEA, 2014), while agencies in China usually do not include it. As a result, shares of natural gas in total energy use are larger when biomass is not counted.

${ }^{2}$ Unconventional natural gas resources include shale gas, tight gas, and coal-bed methane.
} 
time, China's government was promoting an increase in natural gas use. As a result, China's gas supply failed to keep pace with the surging demand and in some places shortage of gas occurred (IEA, 2012).

To deal with the imbalance of demand and supply, the Chinese government launched a set of policies to encourage domestic and imported gas supply expansion, and promote efficient gas use, including the nationwide natural gas pricing reform program. The gas pricing reform was introduced in Guangdong and Guangxi provinces in 2011 and was implemented nationwide in 2013. The primary rationale for the pricing reform is that natural gas prices should be determined ultimately in the market (NDRC, 2013). A key element of the new approach is a connection to imported oil and gas prices, as the price of gas is set by the formula that includes a weighted average of the imported fuel oil price and liquefied petroleum gas (LPG) price. These international fuel prices are market-driven and because fuel oil and LPG are close substitutes for natural gas, the formula provides a link to market forces. The new regime has been exercised for three years. Our paper addresses the impacts of the reform and its success in achievement of its policy objectives.

\section{METHODS}

The pricing reform is analyzed as follows. We begin with an overview of the natural gas market in China focusing on the existing and prospective supply and consumption by sector. This overview sets the stage for the analysis, identifying the latest developments in natural gas sector in China. Then we provide an analysis of the old pricing regime and the main dimensions of the pricing reform. We underline the shortcomings of the approaches. China's government documents the new price formula and the resulting natural gas prices by provinces, but they do not provide full information. We perform a price simulation based on the available data to 
compare with the natural gas prices listed by the government. We then analyze the impact of the pricing reform on natural gas producers, distribution companies and end users. Based on our analysis we discuss the major limitations of the current reform and offer some suggestions for the future reform directions.

\section{RESULTS}

\subsection{Overview of the natural gas system in China}

The government of China regards the expansion of natural gas use as a critical component of shifting away from coal-dominated energy structure, necessitated by interest in tackling air pollution problems and reducing carbon emissions. China's natural gas consumption climbed from 46.4 billion cubic meters (bcm) in 2005 to $167.6 \mathrm{bcm}$ in 2013 with an average annual growth rate of $17.4 \%(\mathrm{CNPC}, 2014)^{3}$. As shown in Figure 1, the natural gas share in China's primary energy supply increased from $2.6 \%$ in 2005 to $5.8 \%$ in 2013 (NBS, 2014a) ${ }^{4}$. The natural gas contribution to China's energy supply is well below coal and oil, which were approximately $66 \%$ and 18\%, respectively, in 2013 (also depicted in Figure 1). It is also lower than the global average of $23.7 \%$ in 2013 (BP, 2014). According to China's national energy program during the Twelfth Five Year Plan, a goal for China's natural gas consumption is $230 \mathrm{bcm}$ by 2015, which would account for $7.5 \%$ of the total primary energy consumption (NDRC, 2012). It would mean more than quadrupling of natural gas use in ten years from 2005.

Prior to 2006, China's natural gas supply had come from domestic production sources

(Figure 2). Since then, imports have grown rapidly, especially since 2010, when the Central Asia - China pipeline started operations. By 2013 approximately $31 \%$ of annual natural gas

\footnotetext{
${ }^{3}$ Data from different sources are slightly different. For example, BP reports $46.8 \mathrm{bcm}$ for 2005 and $161.6 \mathrm{bcm}$ for 2013 (BP, 2014).

${ }^{4}$ China usually reports its statistics in million tons of coal equivalence (mtce). $1 \mathrm{mtce}=0.786 \mathrm{bcm}$.
} 
consumption came from imports (CNPC, 2014). The Myanmar - China pipeline and the liquefied natural gas (LNG) receiving terminals in Guangdong, Hebei, and Tianjin started operation in 2013, significantly expanding China's gas import capacity. In 2013, 54\% of China's gas imports were delivered through the Central Asia and Myanmar pipelines, with the rest coming from LNG (CNPC, 2014).

In 2013 China's domestic gas production contributed $115 \mathrm{bcm}$, or approximately $69 \%$ of the total gas supply (Figure 3). Conventional gas production accounts for about 97\% of domestic production. The three top gas basins - Tarim, Ordos, and Sichuan — currently play a dominant role in China's domestic gas supply, accounting for over 90\% of China's total domestic gas production. China's current unconventional gas production capacity is rather limited. The total unconventional gas production was $3.3 \mathrm{bcm}$ or $1.95 \%$ of China's domestic gas supply in 2013, of which coal bed methane (CBM), shale gas, and coal to gas constituted $1.77 \%, 0.06 \%$ and $0.12 \%$, respectively. According to BP (2014), China's natural gas proven reserves are 3,272 bcm. This number does not include more speculative conventional and unconventional resources that we discuss later.

As for imports, the current (2014) import pipeline capacity is $30 \mathrm{bcm}$ for the combined two lines of the Central Asia - China pipeline and $12 \mathrm{bcm}$ for the Myanmar - China pipeline. Construction of a third line of the Central Asia - China pipeline was mostly completed in 2014 and a capacity of $55 \mathrm{bcm}$ for the combined three lines is expected to be operational by the end of 2015. All three lines originate in Turkmenistan, and pass through Uzbekistan and Kazakhstan. The first two lines get natural gas from Turkmenistan, while for the third line some additional gas from Uzbekistan $(10 \mathrm{bcm})$ and Kazakhstan (current amounts are not specified, a potential expansion to Kazakhstan gas fields on the Caspian Sea would create another sizeable source of 
supply) is contracted as well. The pipelines are connected to China's West-East gas pipeline that goes from its western border and pass through China all the way to Shanghai.

A fourth line (with a capacity of $30 \mathrm{bcm}$ ) of the Central Asia - China pipeline is under construction with an expected completion by 2020. This line will also originate in Turkmenistan, but it will pass through Uzbekistan, Tajikistan and Kyrgyzstan. Out of the total capacity of 85 bcm planned for 2020, Turkmenistan has signed an agreement of supplying $65 \mathrm{bcm}$ annually to China starting from 2020.

China has also signed an agreement with Russia to supply $38 \mathrm{bcm}$ by 2018 from the Power of Siberia pipeline. An advantage of this project is that it will cross China's border in the NorthEast side with a close proximity to industrial centers rather than supplying gas through the China's West-East pipeline. Another pipeline (called Altai, with $30 \mathrm{bcm}$ capacity) from Russia is under consideration. The Altai pipeline is expected to be connected to the Russian fields that currently supply Europe. In China it would be linked to the West-East pipeline. As for another import option, LNG, in 2014 China had 12 regasification terminals with a combined capacity of about 50 bcm, or 35 million tonnes (Mt) of LNG (Interfax, 2015).

It is expected that by 2020 China will have an estimated pipeline import capacity of $165 \mathrm{bcm}$ (85 bcm from Cenral Asia, 12 bcm from Myanmar, and 68 bcm from Russia). It is also expected that by 2020 LNG import capacity would reach $88 \mathrm{bcm}$. Another $58 \mathrm{bcm}$ of LNG capacity has been proposed, but these projects can be postponed or cancelled depending on natural gas demand development (BMI Research, 2013; Du and Paltsev, 2014). In total, by 2020 China’s import capacity (both pipeline and LNG) will be $223 \mathrm{bcm}$ considering existing capacity and the projects under construction. Another $88 \mathrm{bcm}$ is possible if both the Russia's Altai pipeline and additional LNG projects move forward. 
Turning from import capacity to consumption, China's natural gas consumption by sector from 2005 to 2013 is presented in Figure 4. In 2005, most of consumption occurred in three sectors: as a fuel in industry (36\%), as feedstock in chemical production (30\%), and residential use (17\%). Consumption in the power and heating sector and the transport sector was very limited in 2005, but increased rapidly from 2008 and so that by 2013 these two sectors accounted for $30 \%$ of gas consumption.

As of 2013, industry was still the largest natural gas user in China. It consumed approximately $50 \mathrm{bcm}$ of gas and accounted for $31 \%$ of the total gas consumption. The residential sector consumed $30 \mathrm{bcm}$ and accounted for $19 \%$ of the total consumption. The power $\&$ heating sector became the third largest gas user in China and accounted for $18 \%$ of China's total natural gas consumption, followed by chemicals (16\%) and transport (12\%), as shown in Figure 4. Gas use increased substantially in all sectors except for chemicals, hence most of the increased gas consumption has been used as fuel by substituting for coal rather than as a feedstock for the production of chemical products. This largely reflects China's natural gas policy that discourages use of gas as a feedstock in the chemical sector, while encourages fuel switching from coal to gas to tackle air pollution and mitigate $\mathrm{CO}_{2}$ emissions (NDRC, 2012).

Over the past decade, China has increased its efforts in constructing the natural gas pipeline distribution systems. As a consequence, around $32 \%$ of medium and large sized cities in China (with a total population of approximately 240 million) have access to gas pipelines (CNPC, 2014). Figure 5 shows the picture of China's gas consumption by regions. As denoted by blueshaded areas in Figure 5, natural gas consumption is mainly concentrated in four regions: Southwest (Sichuan, Chongqing), Bohai Bay Area (Liaoning, Beijing, Tianjing, Shandong, Hebei), Yangtze River Delta (Shanghai, Jiangsu, Zhejiang), and the Southeast Coastal Area 
(Fujian, Guangdong). These four regions together contributed to more than $60 \%$ of China's gas consumption in 2012 (NBS, 2014). Large consumption of gas in the Southwest (Sichuan and Chongqing) and Xinjiang is because they are located in the major natural gas production areas of China. The major gas consumers in the eastern coastal area of China such as Beijing, Tianjin, Shanghai, Jiangsu, and Guangzhou are among China’s most developed provinces. The rapid growth of natural gas consumption in these rich areas is largely attributed to their efforts to promote the substitution of gas for coal to reduce the frequent smog incidence which has recently caused unprecedented health concerns in these areas.

Relative to these consumption centers depicted in Figure 5, major domestic producing areas are Tarim in Xinjiang, Ordos (located in part in Shaanxi, Shanxi, Gansu, Ningxia), and Sichuan. As for the points of entry for imports, the pipeline from Central Asia enters China in Xinjiang. The pipeline from Myanmar goes to Yunnan, Guizhou, and Guangxi. The Power of Siberia pipeline from Russia will enter in Heilongjiang with a potential to reach Jilin, Liaoning, and Beijing. LNG terminals are located in coastal provinces.

\subsection{The pricing regime before the reform}

China's natural gas pricing has been highly regulated. Before the new pricing regime was introduced nationwide in July 2013, China's pricing approach was characterized as costs plus profit margin. Figure 6 presents the institutional framework of the old pricing regime. The key players in the old approach included National Development and Reform Commission (NDRC), the central government pricing authority, provincial/local government pricing agencies, gas producers/importers, transmission operators, and gas users.

The natural gas price formulation process involved ex-plant price, transmission tariff, city gate price, distribution fee, and end user price. Below we discuss these components. 
Ex-plant prices were determined by NDRC based on price proposals prepared by gas producers. The ex-plant prices were also differentiated by users. For example, the ex-plant prices were different for large users (some industrial users and fertilizer manufactures, denoted as "Direct user" in Figure 6), smaller industrial, transport and residential gas users (that face "Retail prices" in Figure 6). Ex-plant prices were formulated based on a costs-plus-appropriate margin pricing approach as shown by the formula below that includes wellhead cost, purification fee, and applicable taxes and margins. Producers and buyers were able negotiate up to $10 \%$ price increase or decrease based on the ex-plant prices set by the NDRC.

$$
\text { Ex-plant price }=\text { Wellhead cost }+ \text { Purification fee }+ \text { Taxes }+ \text { Appropriate margin }
$$

The transmission tariff was also determined by NDRC. It was based on the tariff proposals by gas transmission pipeline operators. The pipeline operators and gas producers are often the same companies in China. The transmission tariff is largely determined by the formula below that includes coverage of construction cost, operation cost, taxes and margins, and additional terms based on a distance from the gas source to a user.

$$
\begin{aligned}
\text { Transmission tariff }= & \text { Construction cost }+ \text { Operation cost }+ \text { Appropriate margin } \\
& + \text { Cost Variation of distance from gas source to city gate }+ \text { Taxes } .
\end{aligned}
$$

City gate prices are the wholesale prices that local gas distributors pay to the pipeline operators to purchase gas. Under the old pricing approach, the city gate prices are in principle the sum of the ex-plant price and transmission tariff. Since the ex-plant prices are differentiated by user, the city gate prices are also different for the four categories of users mentioned above. 
The distribution fee is determined by the provincial/local pricing authority, which is often a department of the provincial development and reform commission, based on the fee proposals by local distribution operators. The distribution fee calculation is similar to the transmission tariff calculation as in includes coverage of construction and operation costs and appropriate margins and taxes.

$$
\text { Distribution fee }=\text { Construction cost }+ \text { Operation cost }+ \text { Appropriate margin }+ \text { Taxes }
$$

End user prices are the retail prices that gas consumers pay to local distributors. The retail prices are proposed by the local distributors reflecting the level of the city gate price and the distribution fee and they are set by the local pricing agency after a check of the cost report prepared by the distributor. Since city gate price varies, retail prices for different gas users are also different.

As discussed above, the old pricing regime was established when natural gas was supplied domestically and as such it was based on the cost of domestic production. After 2010, with a substantial increase of natural gas imports by LNG and a pipeline from Turkmenistan, in many situations the city gate prices set by the old pricing approach were much lower than the contract prices for imported natural gas. Natural gas importers incurred significant losses, which discouraged natural gas imports. In addition, being tied to the cost of supply only, the old pricing approach did not reflect the fast growth in natural gas demand. As a result, many cities experienced severe shortages of natural gas (IEA, 2012).

\subsection{Natural Gas Pricing Reform Highlights}

Given the problems that had emerged in gas markets, China launched a national natural gas pricing reform program in the early 2010s. We provide a summary of the key points of the 
reform based on key policy documents (NDRC, 2010; NDRC, 2011). The basic reform was to enable the market to play a more important role in a city gate price formulation, by linking gas price with prices of imported fuels. The reform was tested in two provinces, Guangdong and Guangxi, in 2011 before being implemented nationwide in 2013. Two new concepts have been introduced: an existing volume, defined as the amount of natural gas consumption in 2012, and an incremental volume that is the amount added in 2013, 2014, and 2015 beyond that in 2012. The new pricing approach was applicable only to the incremental volumes of the pipelined natural gas. Pricing of imported LNG and unconventional gas are based on negotiations between producers and users, while the prices for household uses are unchanged from the levels determined by old pricing regime.

A three-step transition process was introduced: 1) in 2013 the nationwide city gate prices for the incremental volumes of natural gases were formulated by the new pricing approach; 2) in 2014 the cite gate prices for the existing volumes were increased and the city gate prices for the incremental volumes were adjusted by the new pricing approach; 3) in 2015 the city gate prices for the existing volumes were scheduled to increase to the level of the incremental volumes and the city gate prices for the incremental volumes were scheduled to be adjusted again by the new pricing approach. As a result, a new single natural gas price for the existing and incremental volumes was scheduled to be formulated by the end of March 2015.

Energy pricing reform is politically sensitive and it involves several conflicts of interests. As China's natural gas was underpriced for a long time because of government control, natural gas prices were expected to increase as a result of the reform. To minimize the political risks associated with the rise in natural gas prices, the Chinese government decided to include the 
division of the natural gas consumption into the existing volume and incremental volume and adopt a differentiated pricing approach.

The primary rationale for the new pricing is that the value of natural gas can be largely represented by the value of its two substitutes in terms of providing energy services - fuel oil used in the industrial sector and liquefied petroleum gas (LPG) used in the residential sector. Based on this rationale, a new natural gas price basis was created. New formula represents a weighted composite of the imported fuel oil price and the imported LPG price. The new natural gas price basis is termed as $P_{C G P I N}$ (City Gate Price for Incremental Volume in Shanghai). The ex-plant prices and retail prices are based on this price. The formula for calculation is set by NDRC as follows (NDRC2011; NDRC 2013).

$$
P_{C G P I N}=K \times\left(\alpha \times P_{F O} \times \frac{H_{N G}}{H_{F O}}+\beta \times P_{L P G} \times \frac{H_{N G}}{H_{L P G}}\right) \times(1+R)
$$

The terms in the formula are: $P_{C G P I N}$ is the city gate price for the incremental volume in Shanghai; $K$ is a constant discount rate to promote gas uses and it is currently set at $85 \%$ by the NDRC; $\alpha$ and $\beta$ are the weights for fuel oil and LPG respectively, representing their relative contribution to China's energy supply; $P_{F O}$ and $P_{L P G}$ are the average imported fuel oil and LPG prices; $H_{N G}, H_{F O}$, and $H_{L P G}$ are the heating value of natural gas, fuel oil and LPG respectively; and $R$ is the value added tax (VAT) rate for natural gas.

Under the new pricing regime, Shanghai is chosen as a starting point for the calculation of natural gas prices because Shanghai is not only a large natural gas consumer but also an important energy trade center in China. Shanghai's city gate price is set by $P_{C G P I N}$. Figure 7 depicts how other natural prices are determined by the institutional framework of the new pricing 
paradigm. The major difference between the new pricing approach and the old one lies in a formulation of the ex-plant prices. While under the old approach the ex-plant price of natural gas was largely based on the production cost, now it is a result of the $P_{C G P I N}$ (or Shanghai's city gate price) minus the transmission tariff for a distance from Shanghai to where the natural gas is produced. The calculation of the transmission tariffs and the retail prices under the new regime, however, is almost the same as under the old approach.

\subsection{Natural Gas Price Adjustment Exercises}

The pricing reform program has been implemented largely through the three NDRC directives on city gate price adjustments released in 2013, 2014, and 2015, respectively. The directives specified the starting dates when new pricing is planned to be implemented, but they did not specify for how long these prices will stay in place and when they will be revised next time.

Figure 8 presents the changes in city gate price by region set by NDRC under the three directives for three periods of time ${ }^{5}$. The first period was governed by the first NDRC directive on city gate price adjustment (NDRC, 2013) and lasted for 417 days from July 10, 2013 to August 31, 2014. As can be seen in Figure 8, the incremental volume price was significantly higher than the existing volume price (which represented natural price levels before the reform). The pricing reform created incentives for natural gas companies to increase natural gas supply because they were able to sell additional gas at higher prices.

NDRC issued its second directive on price adjustment on August 10, 2014 as a second step of natural gas pricing reform (NDRC, 2014). According to the second directive, the existing volume

\footnotetext{
${ }^{5} \mathrm{NDRC}$ reports prices in yuan $/ \mathrm{m}^{3}$. In this report we report prices to $\$ / \mathrm{MMBtu}$ using the following conversion factors: $1000 \mathrm{~m}^{3}$ of natural gas $=35.7 \mathrm{MMBtu}(\mathrm{BP}, 2014), 1 \$=6.16$ yuan (average exchange rate for 2014 from USForex, 2015).
} 
price was increased by $0.55 \$ / M M B t u\left(0.12\right.$ yuan $\left./ \mathrm{m}^{3}\right)$ in Guangdong and Guangxi ${ }^{6}$, and was increased by $1.82 \$ / \mathrm{MMBtu}\left(0.40 \mathrm{yuan} / \mathrm{m}^{3}\right)$ in the other provinces. The incremental volume price was left unchanged. As demonstrated in the middle panel of Figure 8, the price gap between the existing volume and the incremental volume has been significantly narrowed. This pricing period started from September 1, 2014, and will last until March 31, 2015. This pricing period has 212 days, which is shorter than the first pricing period. The end of the second pricing period was determined by NDRC's third directive on natural gas price adjustment released in February 28, 2015 (NDRC, 2015).

In the third directive, NDRC increased the city gate gas price for the existing volume once more but decreased the city gate price for the incremental volume to a large extent (as shown in the right panel of Figure 8). Since the international price of fuel oil and LPG was lower, the price for the incremental volume fell. With the third price adjustment, the prices for the existing volume of natural gas and for the incremental volume of natural gas reached the same level, indicating the end of the two-tier pricing. The new pricing approach was scheduled to be applied to the pipelined natural gas pricing after April 1, 2015. Indeed, as of April 2015, NDRC has announced elimination of the two-tier natural gas pricing.

A decrease in the city gate price for the incremental volume is affected by a significant drop in the oil price in the international market since October 2014 as shown in Figure 9. Since the new natural gas pricing approach is based on a weighted composite of the imported fuel oil price and the imported LPG price, natural gas prices in the third period of the reform reflect such price changes in the international oil market. There is no information how long the third period will last and when new price recalculation will occur.

\footnotetext{
${ }^{6}$ We could not find a justification why these two provinces have separate schedules for price increase.
} 
As can be seen in Figure 8, the city gate price for the incremental volume is higher than for the existing volume in all provinces, indicating that the introduction of the new pricing approach increased the gas price level for the whole nation. The approaches for local distribution fee charging and retail pricing under the new pricing paradigm are essentially the same as under the old one. In practice, the local pricing authorities take into account a difference in city gas price between the existing volume and the incremental volume when determining the level of retail prices for end users, but often do not provide the existing volume-specific or incremental volume - specific retail prices. Instead, the local authorities provide only one price for each category of gas end users. Such price combines the service prices from the existing volume and incremental volume. Figure 10 lists the end use prices by province in July 2014.

As can be seen, the retail prices vary by province. The average price level for residential use was $11.13 \$ / M M B t u$, which is slightly higher than the average city gate price for existing volume gas supply (which was 9.50 \$/MMBtu during that period), but much lower than the average city gate price for incremental volume gas supply (which was 13.40 \$/MMBtu). The retail price for industry sector averaged at 15.30 \$/MMBtu, ranging from 7.73 \$/MMBtu to 22.05 \$/MMBtu by province. The price level for industrial use is higher than for residential use in all provinces. The retail price for transportation sector is among the highest in all provinces. The average price level for transportation uses was 19.71 \$/MMBtu.

Residential prices for natural gas are lower than industrial in China, which is the opposite of the price levels in developed countries. For example, in USA in 2013 with Henry Hub price of 3.66 \$/MMBtu, delivery prices to electric power users were 4.39 \$/mMBtu, industrial users 4.66 \$/MMBtu, commercial users - 8.44 \$/MMBtu, residential users - 10.54 \$/MMBtu, and transportation - \$15.68 \$/MMBtu (EIA, 2014). In Italy in 2011 residential prices were 19.45 
\$/MMBtu, while prices for industry were 12.05 \$/MMBtu (Honore, 2013). A relationship between residential and industrial prices in China is driven by the desire to subsidize residential use of natural gas.

\subsection{Price Simulations}

Transparency in price formulation is critically important for market players and analysts. Prices provided in Figures 8 and 10 are based on the NDRC documents that give the resulting prices but they do not provide the detailed information on how they are calculated. To replicate the results, we decided to use formula (1) with the publicly available data for inputs. In order to simulate the resulting prices, we follow a procedure depicted in Figure 7. At first, we calculate the $P_{C G P I N}$. Then we determine the ex-plant prices for the major natural gas production areas and also establish the city gate gas prices by region.

Table 1 present the input data provided in NDRC documents. It should be noted that NDRC does not provide all the details of their price calculations. As a result, we have to make several assumptions. First, NDRC states that formula (1) is calculated based on the price of imported fuel oil and imported LPG. However, there is no information on which prices were actually used in their calculation, what are the corresponding data sources, and prices for what period were chosen. We decided to rely on the reputable source for public data on import and export information - China Export and Import Statistics released by General Administration of Customs of China (GACC). We also assumed that prices in formula (1) are the most recent imported fuel oil and LPG prices at the time of the price adjustment announcement. In our price simulations provided here we focus on the third adjustment, so we used the average prices for imported fuel oil and LPG during a period from July 2014 to December 2014. Table 2 shows our assumptions for the imported fuel oil and LPG prices. 
NDRC also did not release the transmission tariffs that they used for the price adjustment. For this information we had to reply on our individual communications with Chinese natural gas experts. Table 3 presents the transmission tariffs of the natural gas transmission pipelines. They are based on a distance from Xinjiang. For example, a tariff from Xinjiang to Gansu is 0.3 yuan $/ \mathrm{m}^{3}$ (or $1.35 \$ / M M B t u$ ), while a tariff from Xinjiang to Shanghai is $1.1 \mathrm{yuan} / \mathrm{m}^{3}$ (or 5.00 \$MMBtu). Figure 11 provides information on geographic locations along the West-East pipeline.

Using the information provided above we re-calculated city gate and ex-plant prices, which are provided in Table 4. Ex-plant prices are estimated to be $1.775 \mathrm{yuan} / \mathrm{m}^{3}$ (which is an equivalent of 7.93\$/MMBtu). NDRC does not provide ex-plant prices in their documents on pricing. Comparing our simulated city gate prices and those provided by NDRC show that they are in a relatively close agreement for most of the locations. The differences are smaller than $4 \%$, except for Shaanxi, where the difference is about 6.5\%. Except for Shaanxi again, our simulated prices are slightly lower than the NDRC prices, which suggest that our assumptions about the input prices and/or transmission tariffs are slightly lower than those used by NDRC. As mentioned before, Shaanxi is a province with a domestic natural gas production and a large portion of its natural gas demand is provided by local production. Price difference there can be explained by negotiations of the local governments with NDRC. There are reports that the Shaanxi municipal government negotiated with the NDRC for a lower gas price.

In general, our simulations show that new pricing mechanism is more transparent than the old regime when price information was hard to obtain. Transparency and predictability can be further improved if the complete information about all inputs required for calculations are 
provided by NDRC. It will help market players to establish a confidence in the new pricing scheme.

\section{DISCUSSION}

\subsection{Impacts on gas producers and importers}

Gas producers and importers appear to benefit the most from the price reform because it causes an increase in the city gate prices and ex-plant prices. Figure 12 shows the natural gas market share (in terms of domestic production) among the three state-owned oil and gas giants PetroChina ${ }^{7}$, Sinopec and CNOOC. These three companies together own and operate over $90 \%$ of China's gas infrastructure covering gas production, import, transmission, and storage business. PetroChina is the largest gas supplier and pipeline operator in China and provided 67.3\% of China's domestic gas supply in 2013.

Below we focus on PetroChina to see the impacts of the natural gas pricing reform. Figure 13 compares the margins of PetroChina's gas and pipeline business under the old and new pricing paradigm. Under the old pricing regime, the ex-plant pricing approach applied for both domestic and imported pipeline gas. According to their 2013 annual report (PetroChina, 2014), in 2012 PetroChina earned about 40 billion yuan on the sales of natural gas and pipeline operations. At the same time, they paid about 42 billion yuan for the imported gas from Central Asia. As a result, the company lost 2 billion yuan in 2012. In 2013, PetroChina paid a similar amount for imported gas, but after the introduction of the new pricing system in 2013 PetroChina earned about 71 billion yuan from the sales of natural gas and pipeline operations. As a result, PetroChina earned 31 billion yuan (or about 5 billion dollars) more in 2013 when natural gas pricing was reformed.

\footnotetext{
${ }^{7}$ PertoChina is controlled and sponsored by China National Petroleum Corporation (CNPC).
} 
The details of the difference in performance in 2012 and 2013 can be illustrated by price information provided in Figure 14. In 2012 and 2013, VAT-included border prices of pipeline imports were similar, 11.10 \$/MMBtu and 11.00 \$/MMBtu, respectively. However, the ex-plant prices at Xinjiang were quite different. In 2012, they were 5.50 \$/MMBtu, while in 2013 they were increased by $1.82 \$ / M M B t u$ for existing volume and by 4.64 \$MMBtu for incremental volume. The new pricing system increased the ex-plant prices and allowed PetroChina to make a profit of 28.9 billion yuan in 2013 .

\subsection{Impacts on distribution companies}

Since the end user gas prices are regulated by the local governments, the interests of natural gas distributors may be undermined if the local distribution companies fail to pass the increase in the city gate price to the end users. We illustrate this issue in Figure 15, which compares the margins of a gas distributor in Harbin City in 2012 and 2013. The distributor sells natural gas to industrial users under the old and new pricing paradigm. Panel (a) of Figure 15 shows the price components under the old pricing. Panel (b) provides information for pricing with new regime for the existing volume. Panel (c) represents pricing information for the new regime for the incremental volume. The data on all three panels in Figure 15 have the same ex-plant price of $7.32 \$ / M M B t u$ (or 1.61 yuan $/ \mathrm{m}^{3}$ ). The old and new pricing regimes added different amount to that price to determine the city gate prices.

Under the old pricing, the city gate price was 8.68 \$MMBtu. Natural gas reform raised the city gate prices to $9.18 \$ / \mathrm{MMBtu}$ for the existing volume and to 13.18 \$/MMBtu for the incremental volume. Under old pricing, gas distributors made a gain of 1.60 \$/MMBtu on a difference between their cost of supply and end user price. After the reform, with the same distribution costs and slightly different taxes, gas distributors now make a profit of 3.11 
\$MMBtu $\left(0.69\right.$ yuan $\left./ \mathrm{m}^{3}\right)$ on the existing volume natural gas being sold to the industrial users, but lose $0.88 \$ / \mathrm{MMBtu}\left(0.19 \mathrm{yuan} / \mathrm{m}^{3}\right)$ on the incremental volume natural gas to the same users. The city gate prices are regulated by NDRC, while the end user prices are regulated by the local governments. Depending on their objectives, they may keep the end user prices low, which may result in a loss of money for a distribution company, as it happened in Harbin.

\subsection{Impacts on end users}

As discussed before, the major end use sectors are industry, residential and power $\&$ heating. In the residential sector, gas tariffs should increase because of the rise in the city gate prices. However, China's retail prices for natural gas are regulated by the local governments. Social stability considerations might give some reluctance for an increase of residential prices. For example, the residential prices were unchanged for years in Shanghai and Beijing, including the period of the pricing reform. Figure 16 compares the retail price for the residential sector, the city gate price for existing volume gas supply, and the city gate price for incremental volume gas supply for the first adjustment period of July 10, 2013 to August 31, 2014 (CNPC, 2014; NDRC, 2013). The retail price for the residential sector is lower than the city gate price for the incremental volumes in most provinces, and for some provinces (e.g., Xinjiang, Ningxia, Sichuan, Jiangsu) even lower than the city gate price for the existing volumes. It means that the natural gas use in the residential sector is subsidized either by the government or by other end users. The natural gas pricing reform at this stage has not substantially affected the residential sector as consumers are protected by the subsidy scheme. For the long term, however, it would be difficult to maintain the current residential gas price level unchanged forever if the cite gate prices keep changing in future. 
The industry prices are higher than residential in all provinces. Figure 17 provides a comparison between the prices for different users for Beijing, Shanghai, and Zhejiang for the first adjustment period. While the residential prices in these provinces were 10.40, 11.40, and 10.90\$/MMBtu, respectively, the industrial prices were 14.70, 18.10, and 22.00\$/MMBtu. The prices in the industrial sector have not been protected by the government. It appears that industry is the sector which is impacted the most by natural gas price increase. Even more, the sector often has to pay for a part of the natural gas use in the residential sector through a cross-subsidy scheme arranged by the local governments.

The third largest natural gas user, the power \& heating sector, is especially sensitive to the changes in natural gas prices. The price of gas as an input and the price of heat as an output are mostly regulated by local governments, while the price of electricity as an output is regulated by the Central government. The price level of the gas use in the power and heating sector varies by province. It is higher than the gas price for the residential sector in all provinces. In Figure 17 we also provide power sector prices in three provinces. The local governments often provide subsidy for the space-heating in households as well as for power generation that contributes to a local air pollution control. In this context, the profitability of the power and heating sector depends heavily on a subsidy from the local governments. Based on natural gas prices for power sector (shown in Figure 17 as 12.10 \$MMBtu for Beijing) and electricity price (that is also regulated by the Central government), we estimate that in Beijing the gas fired combined heat and power plant (CHP) takes a loss of 0.11 yuan for one kilowatt hour ( $\mathrm{kWh}$ ) of energy supply due to the rise in price of gas associated with the new pricing approach ${ }^{8}$.

\subsection{Limitations of the current pricing reform}

\footnotetext{
${ }^{8}$ The estimate is obtained with the following assumptions: Fuel cost accounts for $70 \%$ of the production cost for a typical gas fired CHP in China (Ji et al., 2013), 1 cubic meter of natural gas generates $5 \mathrm{kWh}$ electricity. Electricity price for gas-fired CHP in Beijing is 0.65 yuan/kWh (BMCDR, 2014).
} 
China's natural gas pricing program has been successful in terms of addressing the major deficiencies of the old pricing regime and has made substantial progress toward establishing a market-based natural gas pricing system. It encouraged producers and importers to provide additional natural gas supplies. At the same time, the reform has its limitations. The program has introduced a new pricing approach but a complete market pricing mechanism was not created. The old pricing scheme largely ignored that both supply and demand have their impact on the price formulation. The new pricing approach created a link with international prices of imported fuel oil and LPG, two main substituting products of natural gas, and it reflects the market pricing principles to a larger extent. However, it is still not a true market system, where prices are constantly determined based on the interaction of supply and demand.

Currently, the prices in the new mechanism are established for a period with a starting date, but with no clear indication for the duration of the period when these prices will be in effect. There is also no clear information on the rules and conditions under which the ex-plant price and the city gate price will be changing as a response to the changes in the traded prices of imported fuel oil and LPG. Government authorities provide the city gate prices, but they do not list the data sources used for the prices of imported fuel oil, LPG, and transmission tariff as well. Understanding the exact rules of the price formulation and the duration of the periods for which a new price is set would help natural gas produces and users to make their sound economic decisions that increase the economic welfare of China. Currently, the reform is mostly focused on producers and importers, while the end user prices are still mostly controlled by local authorities. The true market reform allows flexibility in price formulation at all levels. The industry sector and the power and heating sector are the two largest drivers of China's natural gas consumption growth, but they appear to be the biggest losers of the new reform initiative. A 
similar situation is for transport sector. As the pricing reform largely ignores the demand-side dynamics, it may be problematic to expand natural gas use in industry and transportation to achieve the government objective of increasing the contribution of natural gas in China's energy mix.

The new initiative also fails in correcting price distortions and squeezing out cross-subsidies. The natural gas prices in industry and power sectors are higher than in the residential sector, while supply costs in the residential sector are often the highest compared to other sectors. In the liberalized markets of developed countries the gas prices for residential end users are usually among the highest. The new reform initiative has ignored such distortions between the costs and the resulting prices. The new initiative also pays little attention to encouraging competition, which would lower the price levels. In China the three state-owned oil and gas companies dominate natural gas supply. In order to create an efficient natural gas market in China it is important that private companies have the same rights as state-owned companies in terms of the access to natural gas pipelines, LNG facilities, and gas storage facilities.

\subsection{Discussion of the future reform directions}

Though the natural gas pricing reform has made a substantial progress, China needs to take further efforts to achieve its objectives. We offer the following potential directions for the future development.

\section{Develop a more transparent market-based natural gas pricing system and correct price}

distortions. China's natural gas pricing is still not only heavily regulated but also lacks transparency. To improve the situation, NDRC needs to enhance the new pricing approach by setting the clear rules and conditions under which the city gate prices could be adjusted automatically in response to the changes in international oil market price. It will allow creating 
the solid fundamentals for a movement to a complete market-based natural gas pricing system in China. It is also important to start deregulating the distribution market to correct the price distortions in the retail markets. NDRC and the local governments should work together to address the regional institutional barriers to the integration of the wholesale markets with the retail markets.

Encourage competition in the natural gas production and distribution. Competition often leads to a more efficient allocation of resources and ultimately to lower prices. PetroChina, Sinopec, and CNOOC contribute to about $90 \%$ of China's natural gas supply. They also own major pipeline infrastructure. To provide a better efficiency, the government should formulate regulations that will secure equal access to capital, pipeline and distributional infrastructure to private companies. An experience with shale gas in the United States shows an importance of these small and independent companies in the fast development of new production.

\section{Address the market failure barrier to natural gas by internalizing the environmental}

externalities of coal. Establishing a complete market-based natural gas pricing system is important, but, most likely, it would not be enough to substantially increase the contribution of natural gas in China's energy mix. Natural gas is more expensive than coal when prices do not reflect additional costs related to health and environmental effects of the energy use. The government needs to correct this externality, as natural gas produces less pollution than coal, both at the local, regional, and global levels. Natural gas has a relative environmental benefit compared to coal (Zhang et al., 2014), but the current energy pricing is unable to reflect it. A recent study shows that a substantial substitution of natural gas for coal could take place when coal resource tax and/or carbon tax is introduced (Zhang et al., 2015). Coal use reduction is needed to reach China's goals to peak its carbon emissions by 2030 (China Daily, 2014). 
Substituting to natural gas offers such an option and introduction of incentives (e.g., carbon tax or cap-and-trade system) is an efficient mechanism to mitigate emissions (Paltsev et al., 2015).

\section{CONCLUSIONS AND POLICY IMPLICATIONS}

China's top leadership made decisions to deepen its reform at the Party's Third Plenary in 2014, emphasizing the decisive role of the market in resources allocation (Xinhua Net, 2015). A market-oriented natural gas pricing reform is in line with China's national reform policy. NDRC's natural gas pricing reform aims at establishing a market-based natural gas pricing system, ultimately increasing the contribution of natural gas in China's energy supply mix. Such increase will most likely rely both on domestic production and imports. Despite the large resource estimates ${ }^{9}$, China's experience with shale gas production so far has not provided the same results as the "shale gas revolution" in the United States. In addition to geological, land ownership and water issues, natural gas prices and infrastructure developments are among the limiting factors. With successful resolution of these issues, China has a potential to become a major natural gas producer by mid-century (Paltsev et al., 2013). A successful price reform will also help in finding the right balance of import infrastructure development (both pipeline and LNG) and domestic production.

Experiences of the U.S., where natural gas prices are determined by interaction of supply and demand, and the E.U., where the regions are segmented and some prices are still linked to oil, offer an illustration of the relative efficiencies of the gas pricing mechanisms and benefits of moving to a more complete market system. A complete natural gas pricing reform in China would allow natural gas producers and importers to provide adequate amounts of natural gas and eliminate shortages. Competition will push producers to be more efficient thereby providing a

\footnotetext{
${ }^{9}$ EIA (2013) estimated that China's shale resource is around 30,000 bcm, which is larger than their estimate for the USA of about $20,000 \mathrm{bcm}$.
} 
greater value for the scarce resource. At the same time, careful market design and pacing of the reform is needed to minimize the potential negative effects, such as monopolistic power and impacts on consumers from different income groups.

The new natural gas pricing regime in China has a better predictability and transparency compared with the old pricing regime. It has a strong connection with the international fuel oil market and LPG prices. To minimize potential political opposition during the new regime implementation, the government adopted a two-tier pricing approach for the period of transition. Because it focuses mostly on a supply side, the current reform falls short in establishing a truly market pricing system. Among the major limitations of the current reform is a failure to address the issues at the level of local distribution and retail prices. It also has created biased incentives and favors the large natural gas suppliers. An immediate step for improving the new pricing approach would be to set the transparent rules and conditions under which the city gate natural gas prices could be adjusted automatically in response to the changes in international oil and gas market prices. For a long-term development, the Chinese government should investigate the pathways for moving to a complete market-based natural gas pricing system. It will establish a better resource allocation system and results in an increased welfare of China.

\section{Acknowledgements}

We are thankful to industry representatives in China (Shell, CNPC) for their valuable contribution regarding natural gas information and to four anonymous referees for their useful suggestions. The MIT Joint Program on the Science and Policy of Global Change, where the authors are affiliated, is supported by the U.S. Department of Energy, Office of Science under grants DE-FG02-94ER61937, DE-FG0208ER64597, DE-FG02-93ER61677, DE-SC0003906, DE- SC0007114, XEU-0-9920-01; the U.S. Department of Energy, Oak Ridge National Laboratory under Subcontract 4000109855; the U.S. Environmental Protection Agency under grants XA-83240101, PI-83412601-0, RD-83427901-0, XA83505101-0, XA-83600001-1, and subcontract UTA12-000624; the U.S. National Science Foundation under grants AGS-0944121, EFRI-0835414, IIS-1028163, ECCS-1128147, ARC-1203526, EF-1137306, 
AGS-1216707, and SES-0825915; the U.S. National Aeronautics and Space Administration under grants NNX06AC30A, NNX07AI49G, NNX11AN72G and Sub Agreement No. 08-SFWS-209365.MIT; the U.S. Federal Aviation Administration under grants 06-C-NE-MIT, 09-C-NE-MIT, Agmt. No. 410330368; the U.S. Department of Transportation under grant DTRT57-10-C-10015; the Electric Power Research Institute under grant EP-P32616/C15124, EP-P8154/C4106; the U.S. Department of Agriculture under grant 58-6000-2-0099, 58-0111-9-001; and a consortium of 35 industrial and foundation sponsors (for the complete list see: http://globalchange.mit.edu/sponsors/all).

\section{REFERENCES}

BMCDR, 2014. Notice of the Beijing Municipal Commission of Development and Reform on Adjusting Feed-in Tariff for Gas-fired Power Plants. Beijing Municipal Commission of Development and Reform. (http://www.bjpc.gov.cn/zcfg10/201407/t7974534.htm)

BMI Research, 2013. Turkmen Gas in the Pipeline for 2020. (http://www.bmiresearch.com/news-andviews/turkmen-gas-in-the-pipeline-for-2020)

BP, 2014. Statistical Review of world Energy 2014, BP plc, London, UK.

China Daily, 2014. China, US unveil ambitious climate change goals, November 12, 2014, (http://www.chinadaily.com.cn/china/2014-11/12/content_18902550_2.htm)

CNPC, 2014. Domestic and Overseas Petroleum and Natural Gas Industry Development Report 2013. China National Petroleum Corporation, Economics \& Technology Research Institute.

Du, Y. and S. Paltsev, 2014. International Trade in Natural Gas: Golden Age of LNG? MIT Joint Program on the Science and Policy of Global Change, Report 217, Cambridge, MA. (http://globalchange.mit.edu/research/publications/2862)

EIA, 2013. Technically Recoverable Shale Oil and Shale Gas Resources: An Assessment of 137 Shale Formations in 41 Countries outside the United States. U.S. Energy Information Administration. (http://www.eia.gov/analysis/studies/worldshalegas/)

EIA, 2014. Annual Energy Outlook 2014, U.S. Energy Information Administration.

EIA, 2015. Petroleum \& Other Liquids: Europe Brent Spot Price FOB (monthly data). U.S. Energy Information Administration. (http://www.eia.gov/dnav/pet/hist/LeafHandler.ashx?n=PET\&s=RBRTE\&f=M)

EPA, 2014. Greenhouse Gas Equivalencies Calculator: Calculations and References. U.S. Environmental Protection Agency. (http://www.epa.gov/cleanenergy/energy-resources/refs.html)

GACC, 2014a. Major Import Commodity Statistic December 2014. General Administration of Customs of the People's Republic of China. (http://www.customs.gov.cn/publish/portal0/tab49667/info730494.htm)

GACC, 2014b. Major Import Commodity Statistic June 2014. General Administration of Customs of the People's Republic of China. (http://www.customs.gov.cn/publish/portal0/tab49667/info713485.htm)

Honore, A., 2013. The Italian Gas Market: Challenges and Opportunities, The Oxford Institute for Energy Studies, Working Paper NG-76. http://www.oxfordenergy.org/wpcms/wpcontent/uploads/2013/06/NG-76.pdf

HPB, 2013. Notice on Adjusting Pipeline Gas Prices. Harbin Pricing Bureau. 
(http://www.harbin.gov.cn/info/news/index/detail1/220387.htm)

IEA, 2012. Gas Pricing and Regulation -China's Challenges and IEA Experience. International Energy Agency.

Interfax, 2015. China's LNG Import Terminals Half-Idle in 2014, Natural Gas Daily, Interfax, (http://interfaxenergy.com/gasdaily/article/15316/chinas-Ing-import-terminals-half-idle-in-2014)

$\mathrm{Ji}, \mathrm{G}$., and Cheng, M. , 2013. Suggestions for the development of Gas-fired Power Plants in Jiangsu Province. Datang News. (http://www.cdt$\mathrm{kjcy} . \mathrm{com} / \mathrm{second} /$ index.aspx? nodeid=15\&page=ContentPage\&contentid=598)

NBS, 2014a. Online Database. National Bureau of Statistics of the People's Republic of China (http://data.stats.gov.cn/english/easyquery.htm?cn=C01)

NBS, 2014b. China Energy Statistic Yearbook 2013. National Bureau of Statistics of the People's Republic of China.

NDRC, 2007. Notice of the National Development and Reform Commission on Increasing the Ex-plant Prices for Domestic Natural Gas Production 2007. National Development and Reform Commission of China.

(http://www.cqpn.gov.cn/UploadFiles/20071211111439529.doc)

NDRC, 2010. Notice of the National Development and Reform Commission on Increasing the Ex-plant Prices for Domestic Natural Gas Production 2010. National Development and Reform Commission of China. (http://www.sdpc.gov.cn/zwfwzx/zfdj/jggg/tyq/201005/t20100531_350435.html)

NDRC, 2011. Notice of the National Development and Reform Commission on Adjusting the Natural Gas Prices in Guangdong and Guangxi provinces. National Development and Reform Commission of China.

(http://www.sdpc.gov.cn/zwfwzx/zfdj/jggg/tyq/201112/t20111227_452950.html)

NDRC, 2012. 12th Five-Year Plan for Natural Gas. National Development and Reform Commission of China (http://www.gov.cn/zwgk/2012-12/03/content_2280785.htm)

NDRC, 2013. Notice of the National Development and Reform Commission on Adjusting the Natural Gas Prices 2013. National Development and Reform Commission.

(http://www.gov.cn/gzdt/2013-06/28/content_2436328.htm)

NDRC, 2014. Notice of the National Development and Reform Commission on Adjusting the Natural Gas Prices 2014. National Development and Reform Commission of China. (http://www.sdpc.gov.cn/zwfwzx/zfdj/jggg/tyq/201408/t20140812_622008.html)

NDRC, 2015. Notice of the National Development and Reform Commission on Adjusting the Natural Gas Prices 2015. National Development and Reform Commission of China. (http://www.sdpc.gov.cn/zcfb/zcfbtz/201502/t20150228_665694.html)

NEA, 2014. Energy Development strategy Action Plan (2014-2020). National Energy Administration of China.

(http://www.nea.gov.cn/2014-12/03/c_133830458.htm)

Paltsev, S., F. O'Sullivan, and Q. Ejaz, 2013. Shale Gas in China: Can We Expect a "Revolution"? Proceedings of the GTAP Conference on Global Economic Analysis, Global Trade Analysis Project, West Lafayette, IN. (https://www.gtap.agecon.purdue.edu/resources/download/6387.pdf)

Paltsev, S., V. Karplus, H. Chen, I. Karkatsouli, J. Reilly, and H. Jacoby, 2015. Regulatory Control of Vehicle and Power Plant Emissions: How Effective and at What Cost? Climate Policy, in press.

Pang, L., 2015. Overview of China's Natural Gas Imports in 2014. Jan 25, 2015. Busuobuneng.com. (http://www.wusuobuneng.com/archives/16453)

PetroChina, 2002. State Council Approves the Feasibility Study Report for the West-East Pipeline Project and Construction on River Crossings and Southern Yangtze Wetland to Commence. PetroChina 
Company Limited.

(http://www.petrochina.com.cn/ptr/xwxx/201404/39e23fe3a35c4790b2869f65d59a35a0.shtml)

PetroChina,2014. 2013 Annual Report. PetroChina Company Limited

(http://www.petrochina.com.cn/ptr/ndbg/201404/8322800c88fe47f3a4a2b3f859c4e974/files/406

15da8916144309bc9f4960ba35739.pdf)

USForex, 2015. Historical Exchange Rates, http://www.usforex.com/forex-tools/historical-ratetools/yearly-average-rates

Xinhua Net, 2015. Xi Jinpin's Diecourse on the Socialist Market Economy in China. Xinahua Net. (http://news.xinhuanet.com/politics/2015-02/09/c_127474234.htm)

Xinhua News, 2014. City gate prices for non-residential sectors will increase by 20\% in September 2014. Xinhuanet.com. August 13, 2014.

(http://news.xinhuanet.com/energy/2014-08/13/c_126864593.htm)

Xinhua News, 2012. Public Hearing on Proposals to Increase Gas Price for Residential Sector in Harbin. March 26, 2012. Xinhuanet.com

(http://www.hlj.xinhuanet.com/news/2012-03/26/c_131488621.htm)

Zhang, X., V.J. Karplus, T. Qi, D. Zhang and J. He, 2015. Carbon emissions in China: How far can new efforts bend the curve? MIT Joint Program on the Science and Policy of Global Change, Report 267, Cambridge, MA. (http://globalchange.mit.edu/files/document/MITJPSPGC_Rpt267.pdf).

Zhang, X., Myhrvold, N.P., Caldeira, K., 2014. Key factors for assessing climate benefits of natural gas versus coal electricity generation. Environ. Res. Lett. 9, 114022.

Zhao, L., 2011. China's Natural Gas Pricing Dilemma --Reflections on China's Natural Gas Reform. International Petroleum Economics, 1(2), 98-106.

Figure Captions:

Figure 1. Natural gas in China's total energy supply (Mtce). Data source: NBS (2014a).

Figure 2. Supply structure of natural gas in China in 2013 (bcm). Data source: domestic supply data (NBS, 2014a), imports by source (CNPC, 2014).

Figure 3. Supply structure of natural gas in China in 2013. Data source: BP (2014) and personal communications with industry experts.

Figure 4. Gas demand by sector 2005-2013. Data Source: 2005-2012 data (NBS 2014b); 2013 data (personal communication with industry experts).

Figure 5. Gas consumption (in bcm) by region during 2005-2012. The vertical bars for each province are provided for illustrative purposes. They can be compared to the represented 2012 consumption of 15 bcm in Sichuan and 10 bcm in Xinjiang. Data Source: NBS (2014b). 
Figure 6. The institutional framework of the old natural gas pricing regime in China. Source: Adopted from Zhao (2011).

Figure 7. The institutional framework of the new natural gas pricing regime in China. Source: Adopted from Zhao (2011) and modified based on NDRC (2013).

Figure 8. City gate prices by region in China, 2013-2015. Data Source: city gate prices after first adjustment (NDRC, 2013); city gate prices after second adjustment (NDRC, 2014); city gate price after third adjustment (NDRC, 2015). Prices reported by NDRC are converted into $\$ / M M b t u$ using the following conversion factors: $1000 \mathrm{~m}^{3}$ of natural gas $=35.7 \mathrm{MMBtu}(\mathrm{BP}, 2014), 1 \$=6.16$ yuan (average exchange rate for 2014 from USForex, 2015).

Figure 9. Chinese city gate prices for natural gas, weighted average import prices and Brent oil price. Data source: NDRC (2013), NDRC (2014), NDRC (2015), EIA (2015).

Figure 10. End user prices by region in July, 2014. Data Source: CNPC (2014). Prices reported by NDRC are converted into $\$ / M M b t u$ using the following conversion factors: $1000 \mathrm{~m}^{3}$ of natural gas $=35.7$ MMBtu (BP, 2014), $1 \$=6.16$ yuan (average exchange rate for 2014 from USForex, 2015).

Figure 11. West-East natural gas pipeline frame in China. Source: PetroChina (2002).

Figure 12. Major gas suppliers in China in 2013. Data Source: Xinhua News(2014).

Figure 13. Margins of PetroChina's gas and pipeline business in 2012 and 2013. Data source: PetroChina (2014).

Figure 14. Border price vs ex-plant price 2012 \&2013. Data Source: import LNG \& pipeline gas prices (CNPC, 2014), ex-plant prices at Xinjiang (authors' estimates based on NDRC, 2010; NDRC, 2013). Prices are converted into $\$ / M M b t u$ using the following conversion factors: $1000 \mathrm{~m}^{3}$ of natural gas $=35.7$ MMBtu (BP, 2014), $1 \$=6.16$ yuan (average exchange rate for 2014 from USForex, 2015).

Figure 15. Margins of natural gas distributors in Harbin for non-residential use: (a) with old pricing; (b) with new pricing for existing volume; (c) with new pricing for incremental volume. Data source: Ex-plant prices (NDRC, 2010), City gate prices (NDRC, 2013), Distribution costs (Xinhua News, 2012), End user prices (Harbin Pricing Bureau, 2013), Transmission tariffs (authors' estimates based on personal communication with industry experts).

Figure 16. Natural gas prices for residential sector for the first adjustment period. Data Source: CNPC (2014), NDRC (2013).

Figure 17. End user gas prices in Beijing, Shanghai and Zhejiang in the first adjustment period. Data Source: CNPC (2014), NDRC (2013).

Table 1 Data used for city gate price calculation

\begin{tabular}{|l|l|l|}
\hline Parameter & Value & Source \\
\hline $\mathrm{K}$ & $85 \%$ & NDRC 2013 \\
\hline
\end{tabular}




\begin{tabular}{|l|l|l|}
\hline$\alpha$ & $60 \%$ & NDRC 2011 \\
\hline$\beta$ & $40 \%$ & NDRC 2011 \\
\hline HNG & $8000 \mathrm{kcal} / \mathrm{m3}$ & NDRC 2011 \\
\hline HFO & $12000 \mathrm{kcal} / \mathrm{kg}$ & NDRC 2011 \\
\hline HLPG & $10000 \mathrm{kcal} / \mathrm{kg}$ & NDRC 2011 \\
\hline R & $15 \%$ & NDRC 2011 \\
\hline
\end{tabular}

Data source: NDRC (2011), NDRC (2013).

Table 2 Average price of imported fuel oil price and LPG, July 2014-December 2014

\begin{tabular}{|l|l|l|l|}
\hline & Imported Volume (million kg) & $\begin{array}{l}\text { Value (million } \\
\text { yuan) }\end{array}$ & Average price (yuan/kg) \\
\hline Fuel Oil & 8,040 & 28,650 & 3.56 \\
\hline LPG & 12,419 & 57,258 & 4.61 \\
\hline
\end{tabular}

Data source: GACC (2014a), GACC (2014b).

Table 3 Transmission tariffs

\begin{tabular}{|l|l|l|}
\hline From & To & Transmission tariff (yuan/m3) \\
\hline Xinjiang & Gansu & 0.3 \\
\hline & Ningxia & 0.35 \\
\hline & Shaanxi & 0.4 \\
\hline & Shanxi & 0.75 \\
\hline & Henan & 0.85 \\
\hline & Anhui & 0.95 \\
\hline & Jiangsu & 1.05 \\
\hline & Zhejiang & 1.08 \\
\hline & Shanghai & 1.1 \\
\hline
\end{tabular}

Source: Authors' estimates based on communication with industry experts

Table 4 Comparing published regional city gate prices with results from our simulation (yuan/m3)

\begin{tabular}{|l|l|l|l|l|l|}
\hline & Our calculation & & NDRC* & Difference \\
\hline & Transmission Tariff & $\begin{array}{l}\text { Ex-plant } \\
\text { price }\end{array}$ & $\begin{array}{l}\text { City } \\
\text { gate } \\
\text { price }\end{array}$ & $\begin{array}{l}\text { City } \\
\text { gate } \\
\text { price }\end{array}$ & \\
\hline Xinjiang & - & 1.775 & 1.775 & 1.85 & -0.075 \\
\hline Gansu & 0.3 & 1.775 & 2.075 & 2.13 & -0.055 \\
\hline Ningxia & 0.35 & 1.775 & 2.125 & 2.21 & -0.085 \\
\hline Shaanxi & 0.4 & 1.775 & 2.175 & 2.04 & 0.135 \\
\hline Shanxi & 0.75 & 1.775 & 2.525 & 2.61 & -0.085 \\
\hline Henan & 0.85 & 1.775 & 2.625 & 2.71 & -0.085 \\
\hline Anhui & 0.95 & 1.775 & 2.725 & 2.79 & -0.065 \\
\hline Jiangsu & 1.05 & 1.775 & 2.825 & 2.86 & -0.035 \\
\hline Zhejiang & 1.08 & 1.775 & 2.855 & 2.87 & -0.015 \\
\hline Shanghai & 1.1 & 1.775 & 2.875 & 2.88 & -0.005 \\
\hline
\end{tabular}

*Source: NRDC (2015). 
Figures

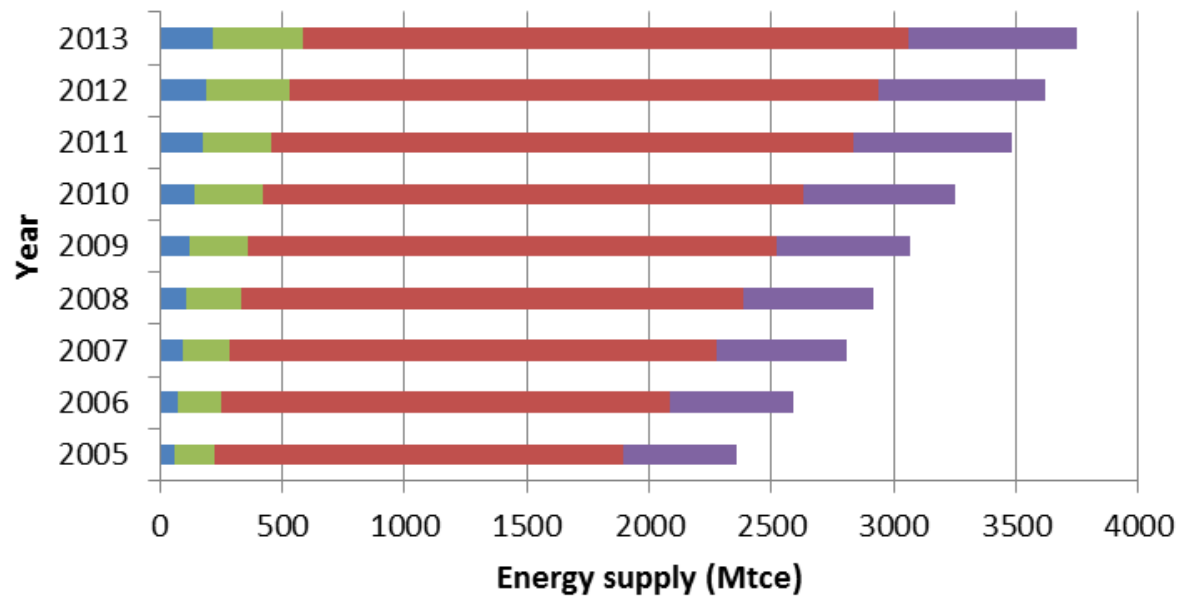

Natural gas non-fossil $\quad$ Coal $\quad$ Petroleum

Figure 1. Natural gas in China's total energy supply (Mtce). Data source: NBS (2014a). 


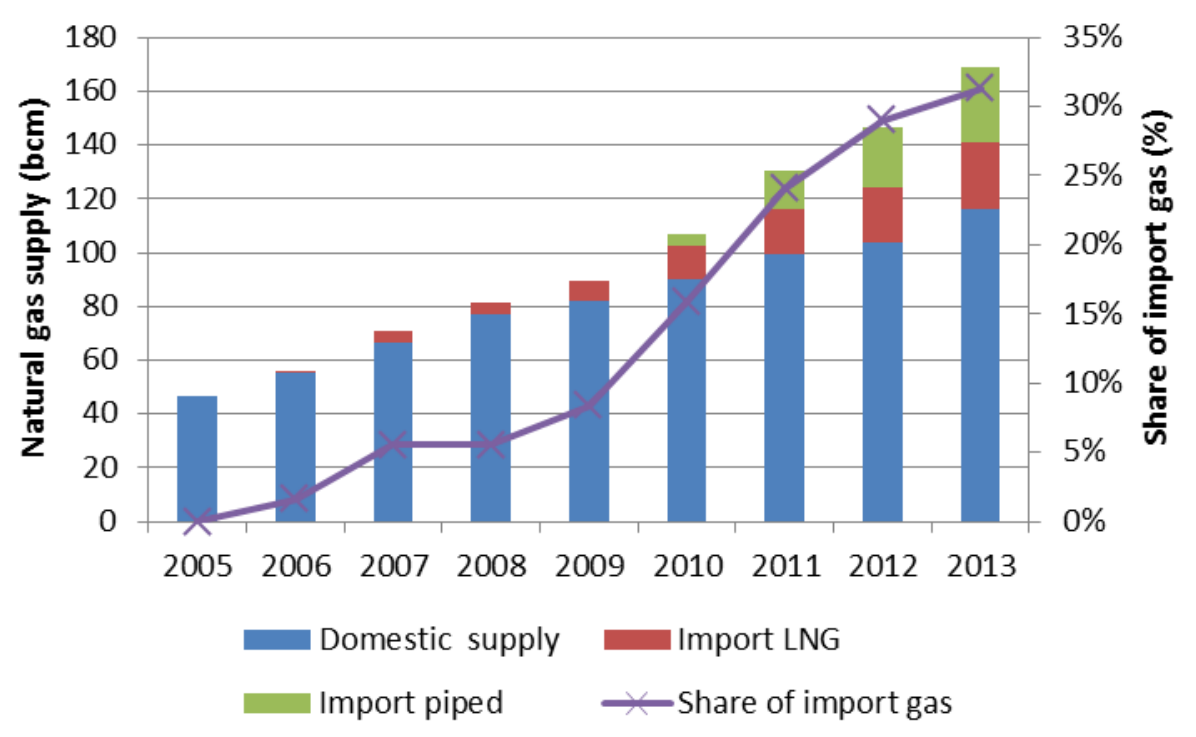

Figure 2. Supply structure of natural gas in China in 2013 (bcm). Data source: domestic supply data (NBS, 2014a), imports by source (CNPC, 2014).

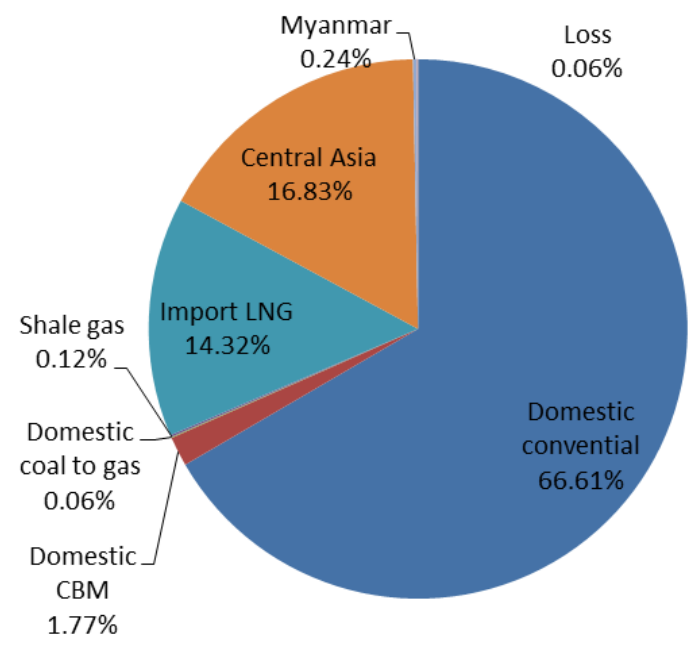

\begin{tabular}{lr}
\hline & $\mathbf{2 0 1 3}$ \\
\hline Domestic: & \\
\hline Convential & 111.6 \\
CBM & 3.0 \\
\hline Shale gas & 0.2 \\
\hline Coal to gas & 0.1 \\
\hline Import: & \\
LNG & 24 \\
Central Asia & 28.2 \\
\hline Myanmar & 0.4 \\
\hline Loss & 0.1 \\
\hline Total & 167.6 \\
\hline & $\mathrm{bcm}$
\end{tabular}

Figure 3. Supply structure of natural gas in China in 2013. Data source: BP (2014) and personal communications with industry experts. 


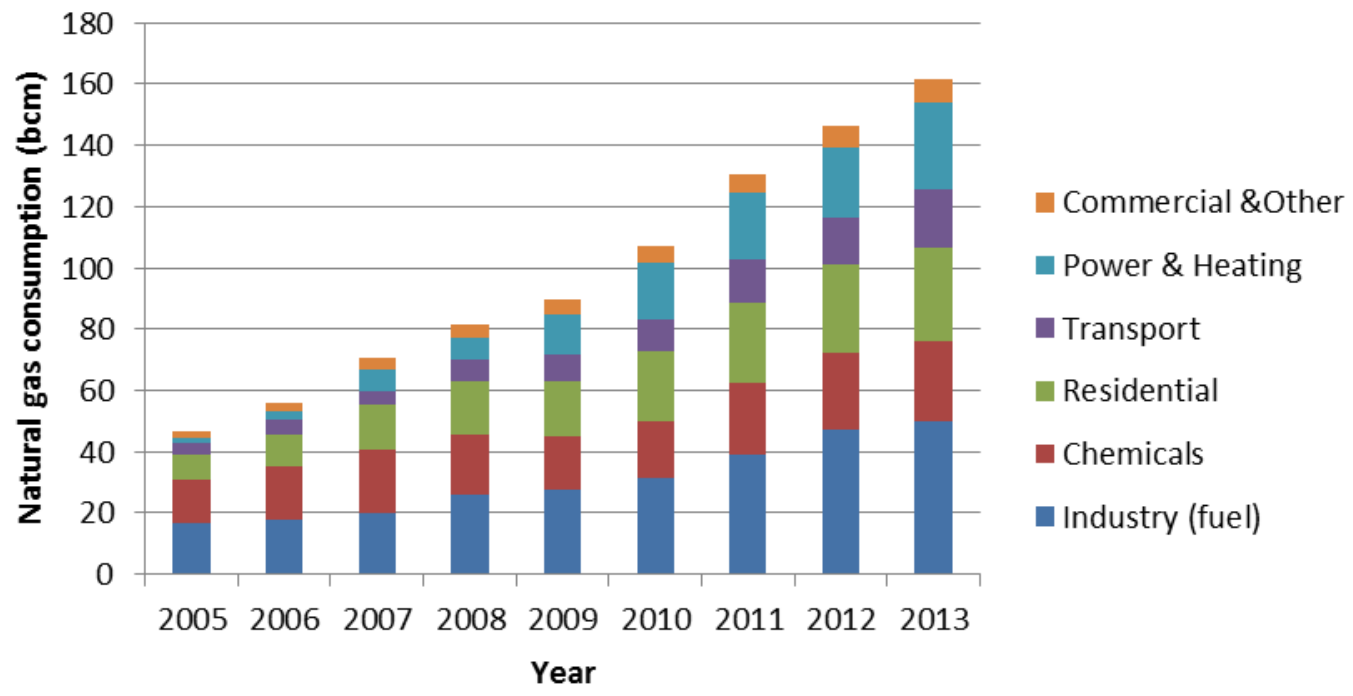

Figure 4. Gas demand by sector 2005-2013. Data Source: 2005-2012 data (NBS 2014b); 2013 data (personal communication with industry experts). 


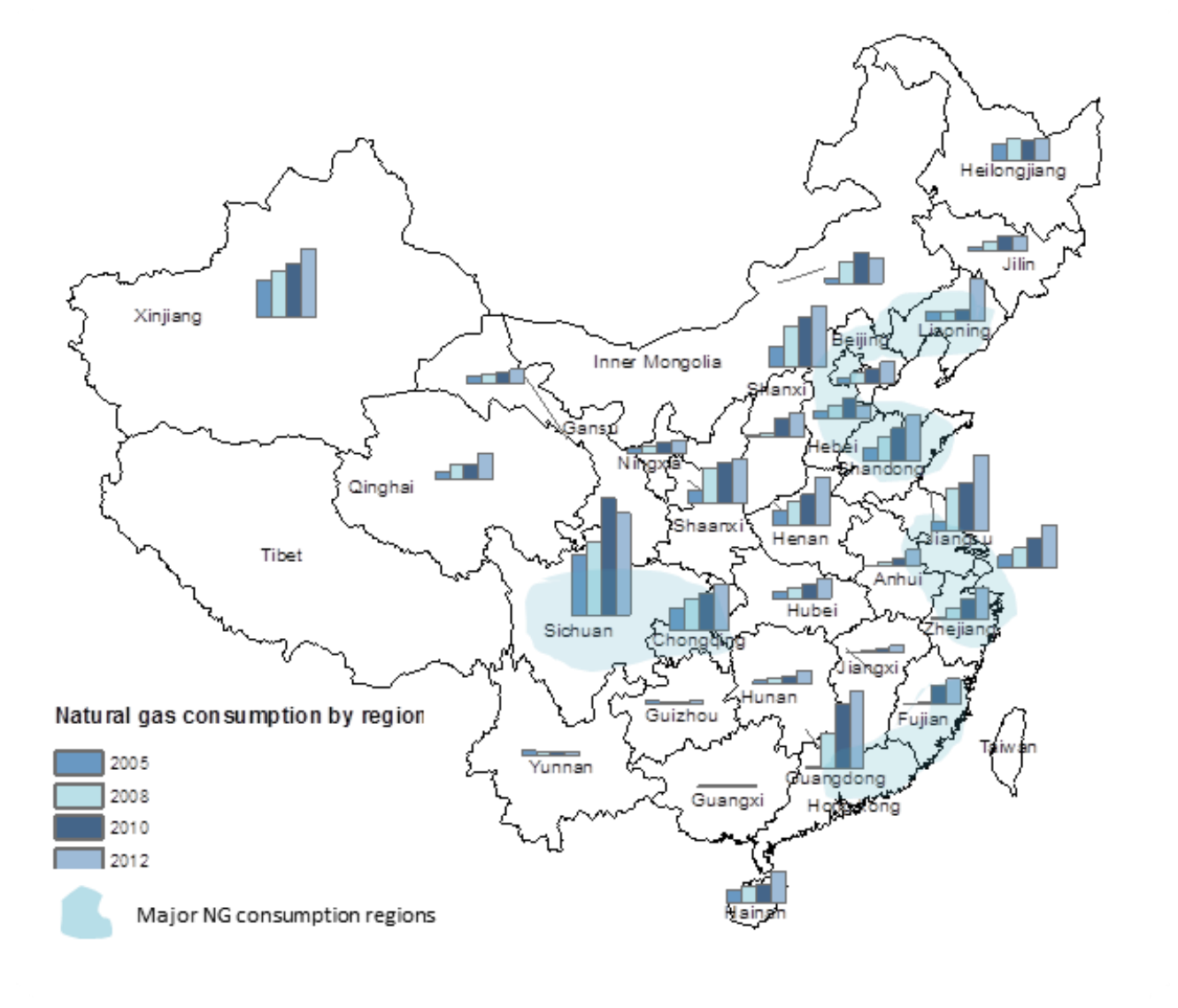

Figure 5. Gas consumption (in bcm) by region during 2005-2012. The vertical bars for each province are provided for illustrative purposes. They can be compared to the represented 2012 consumption of 15 bcm in Sichuan and 10 bcm in Xinjiang. Data Source: NBS (2014b).

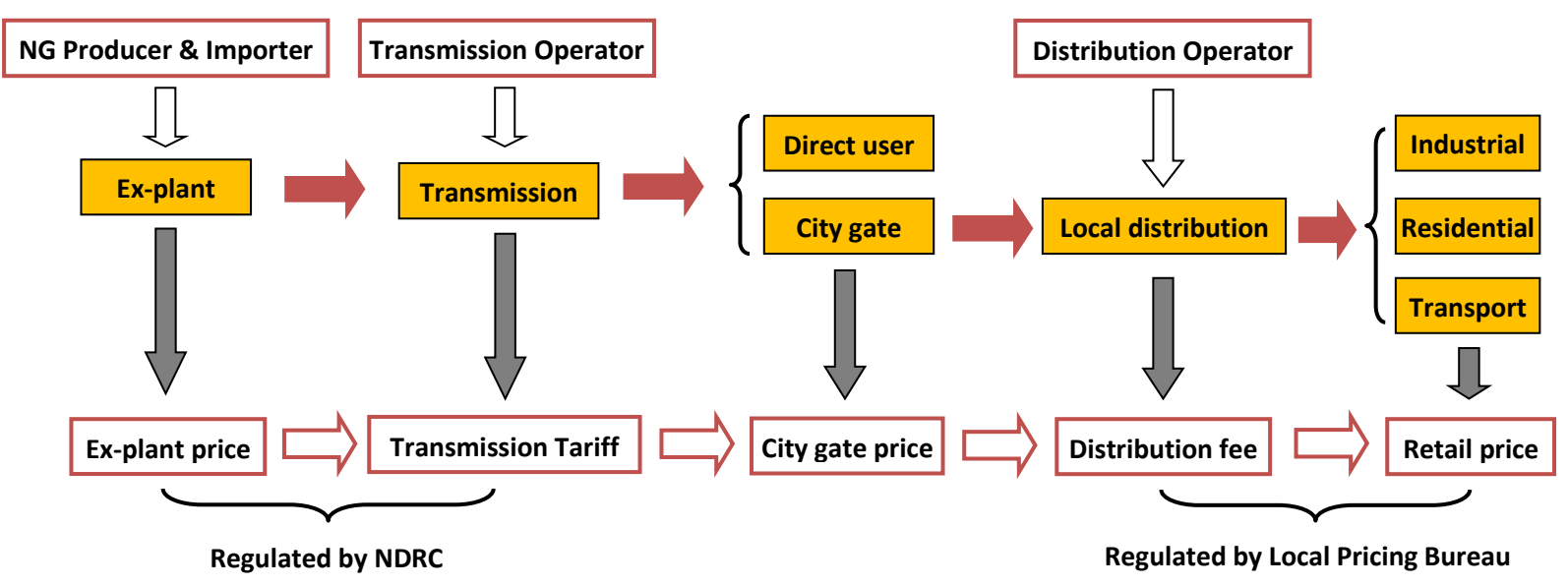

Figure 6. The institutional framework of the old natural gas pricing regime in China. Source: Adopted from Zhao (2011). 


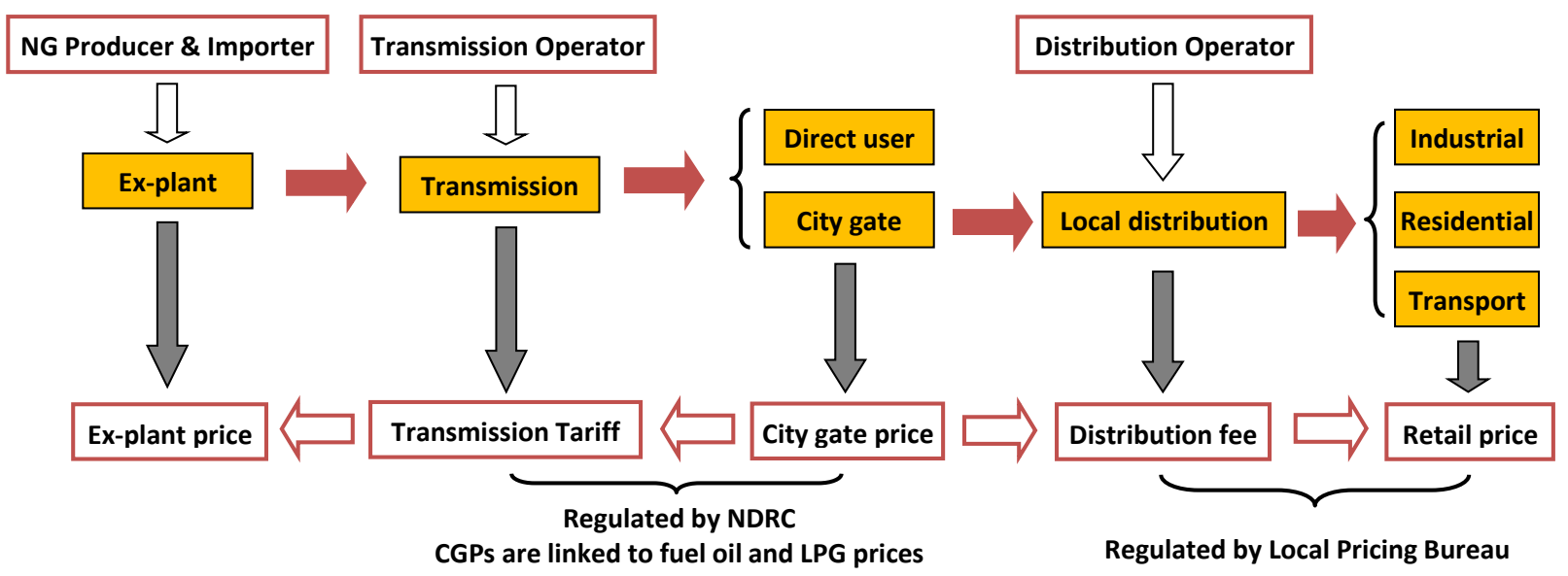

Figure 7. The institutional framework of the new natural gas pricing regime in China. Source: Adopted from Zhao (2011) and modified based on NDRC (2013). 

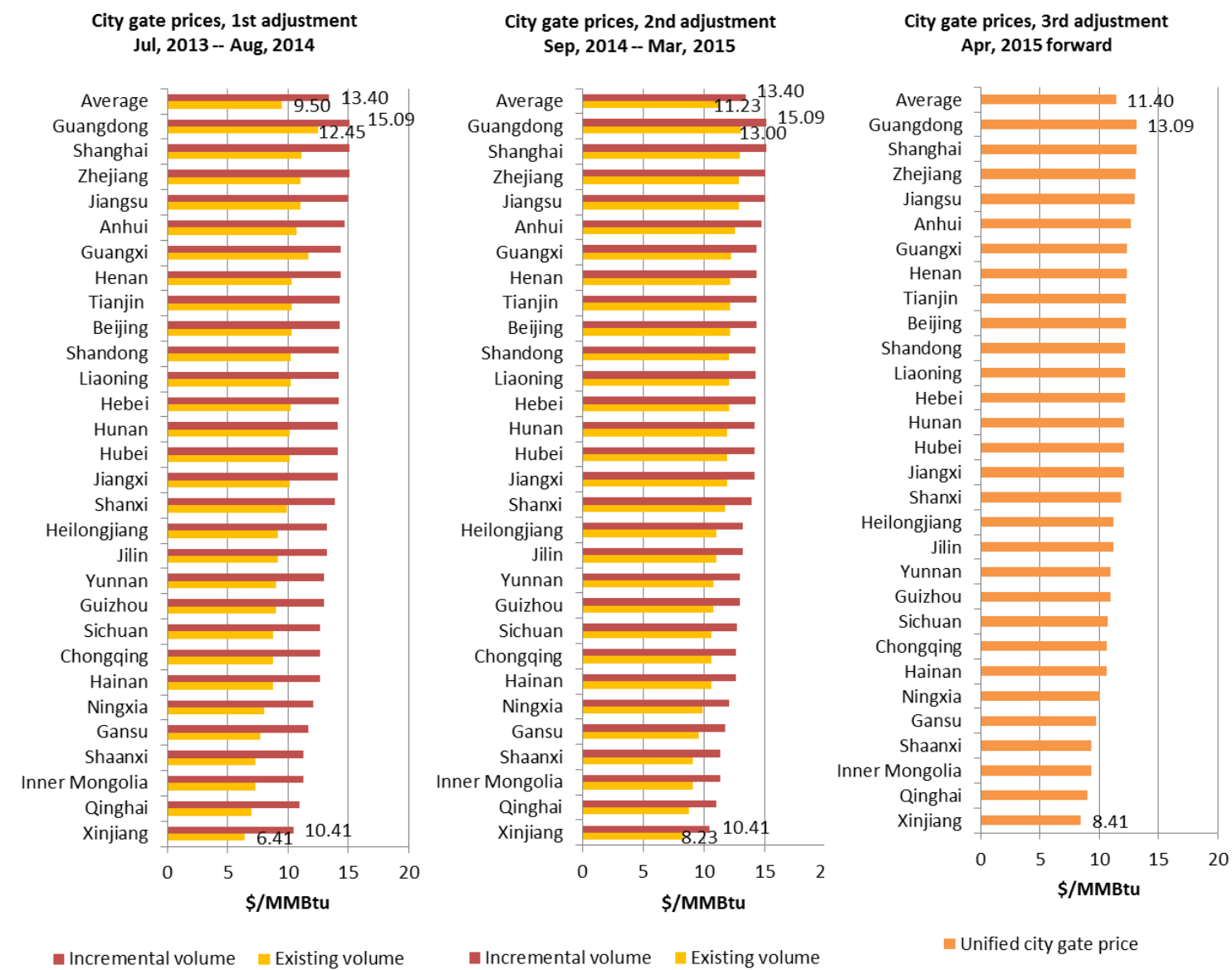

Figure 8. City gate prices by region in China, 2013-2015. Data Source: city gate prices after first adjustment (NDRC, 2013); city gate prices after second adjustment (NDRC, 2014); city gate price after third adjustment (NDRC, 2015). Prices reported by NDRC are converted into $\$ / M M b t u$ using the following conversion factors: $1000 \mathrm{~m}^{3}$ of natural gas $=35.7 \mathrm{MMBtu}(\mathrm{BP}, 2014), 1 \$=6.16$ yuan (average exchange rate for 2014 from USForex, 2015). 


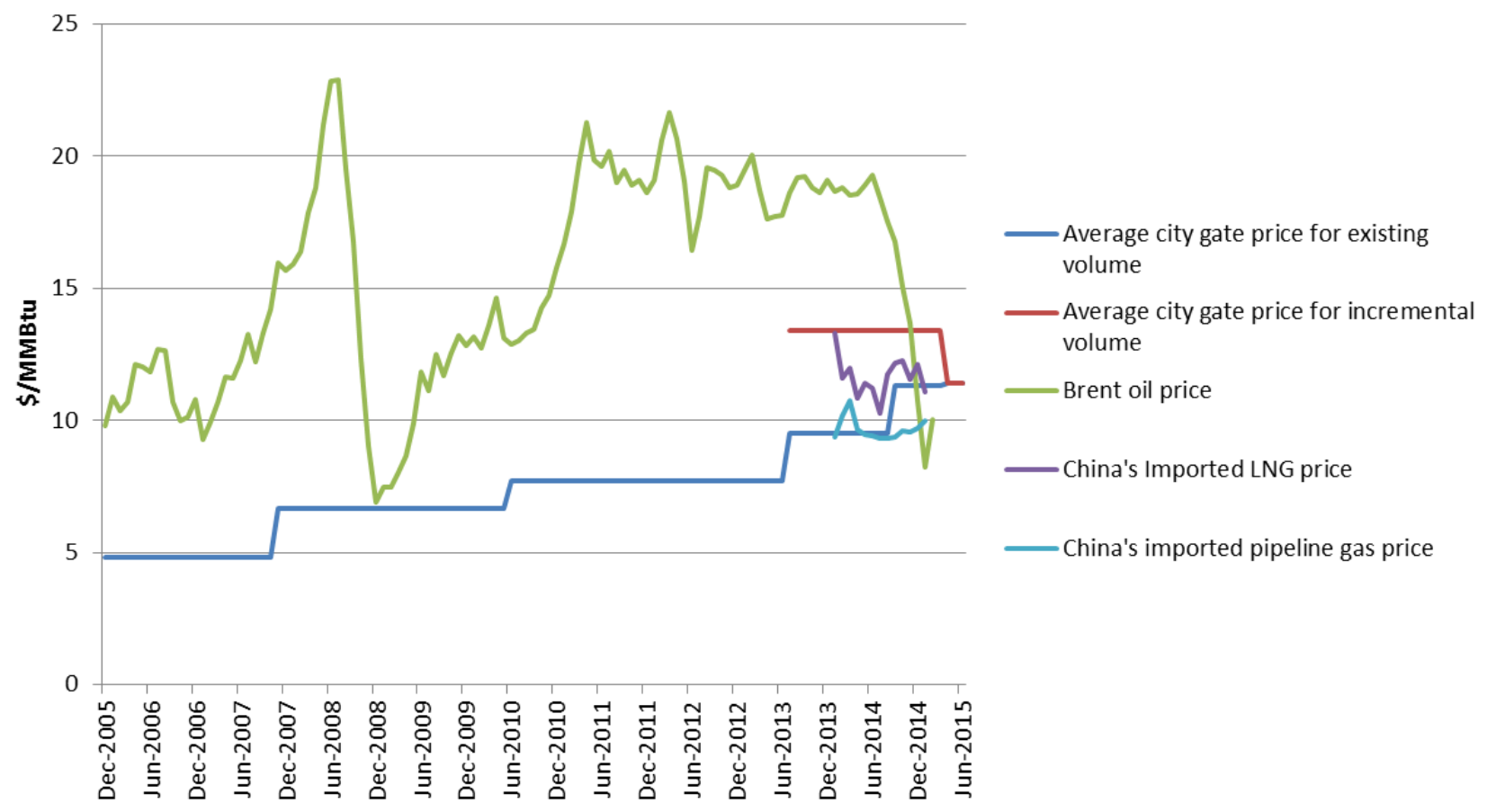

Figure 9. Chinese city gate prices for natural gas, weighted average import prices and Brent oil price. Data source: NDRC (2013), NDRC (2014), NDRC (2015), EIA (2015). 


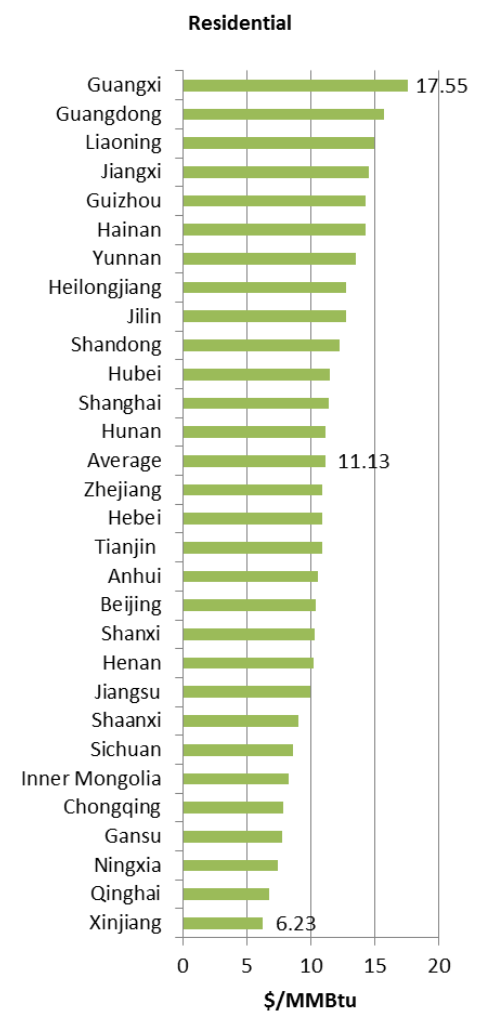

nesidential

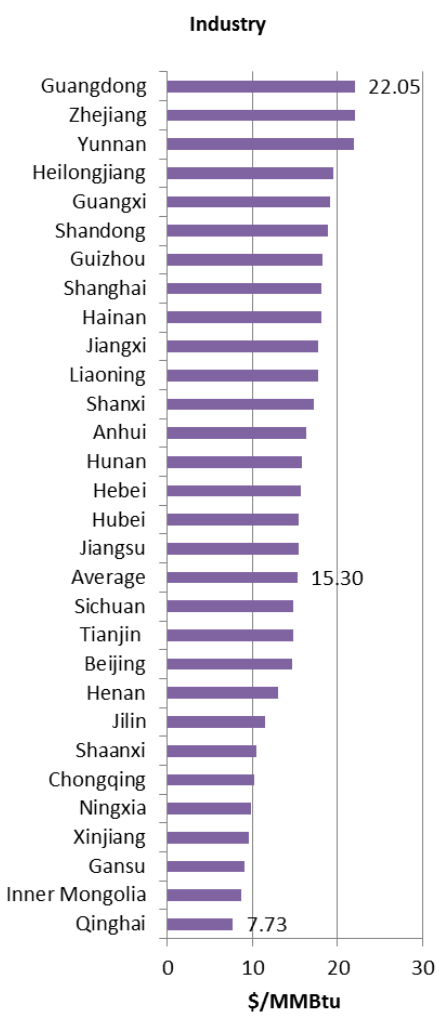

- Industry

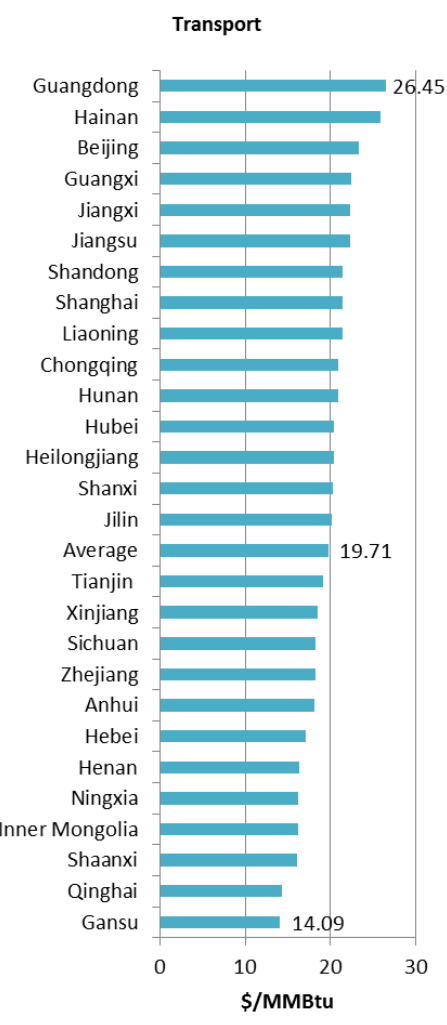

- Transport

Figure 10. End user prices by region in July, 2014. Data Source: CNPC (2014). Prices reported by NDRC are converted into $\$ / M M b t u$ using the following conversion factors: $1000 \mathrm{~m}^{3}$ of natural gas = 35.7 MMBtu (BP, 2014), $1 \$=6.16$ yuan (average exchange rate for 2014 from USForex, 2015). 


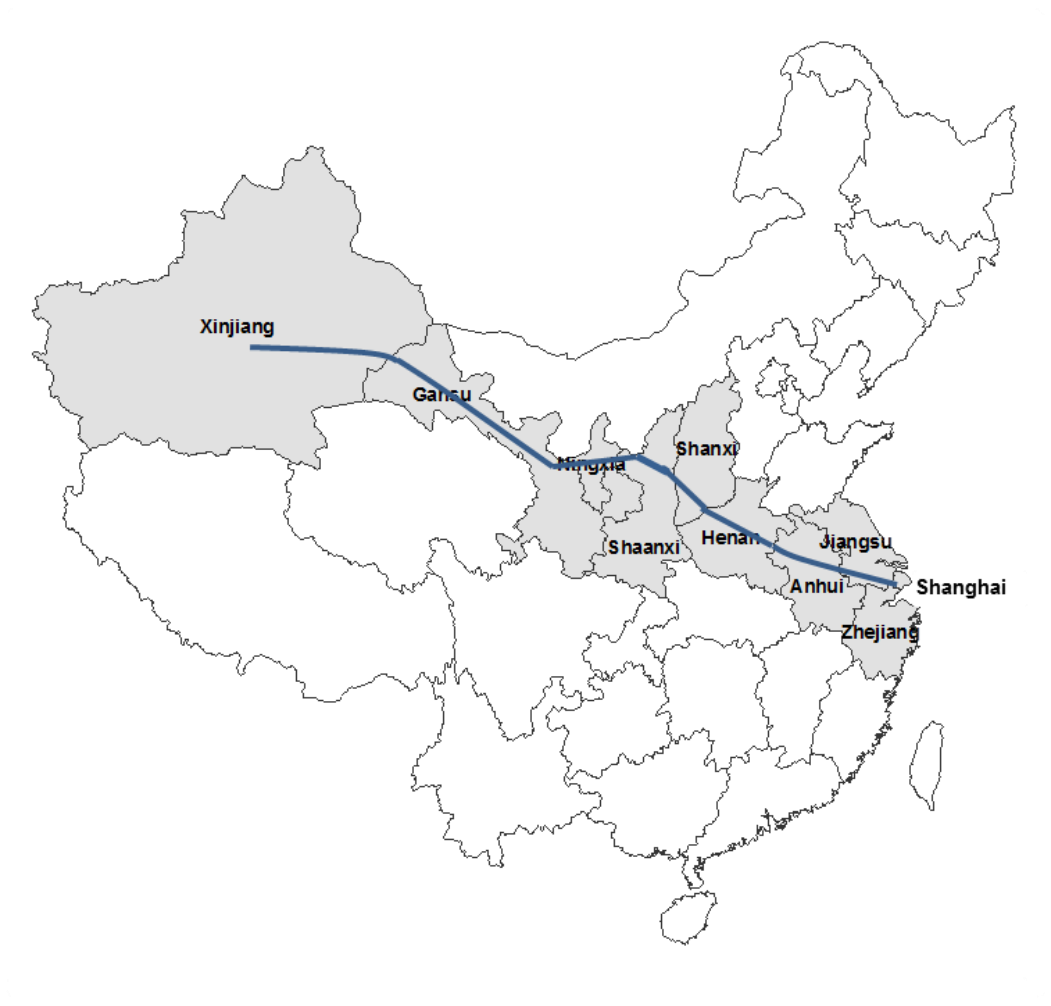

Figure 11. West-East natural gas pipeline frame in China. Source: PetroChina (2002).

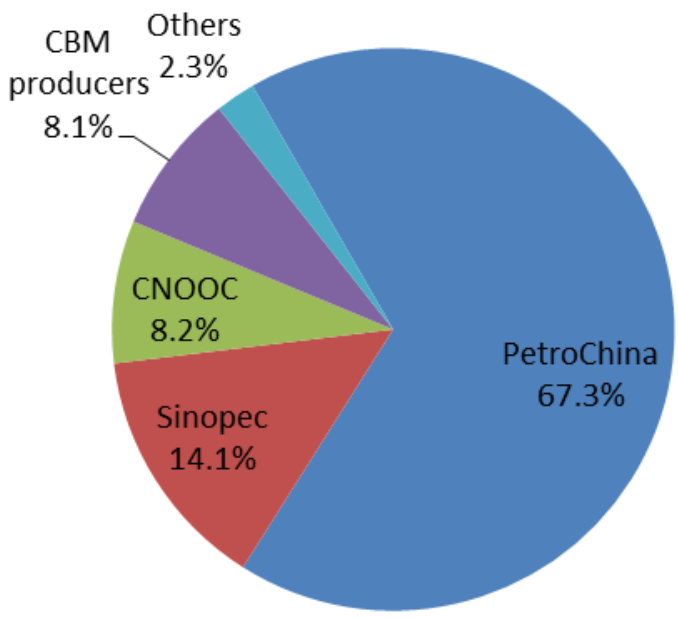

Figure 12. Major gas suppliers in China in 2013. Data Source: Xinhua News(2014). 


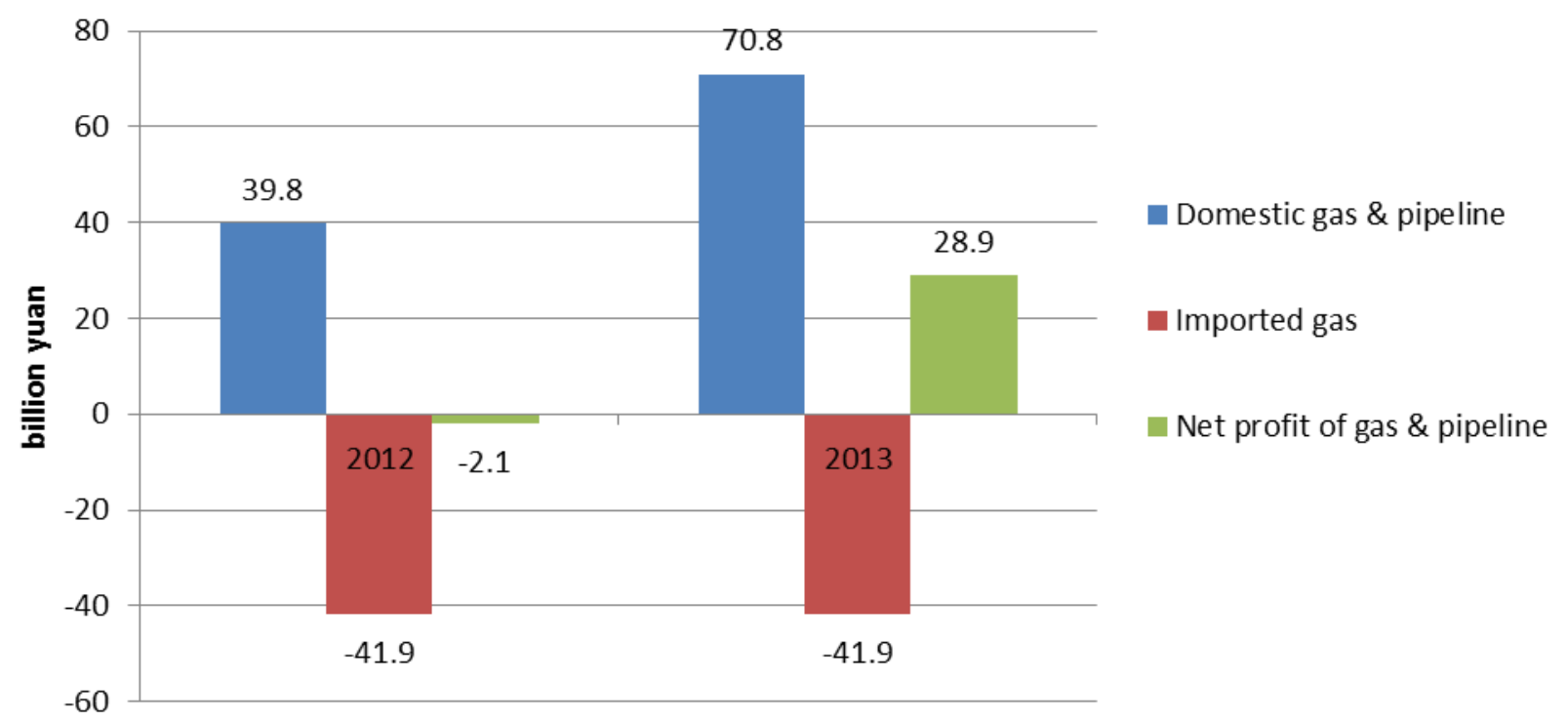

Figure 13. Margins of PetroChina's gas and pipeline business in 2012 and 2013. Data source: PetroChina (2014).

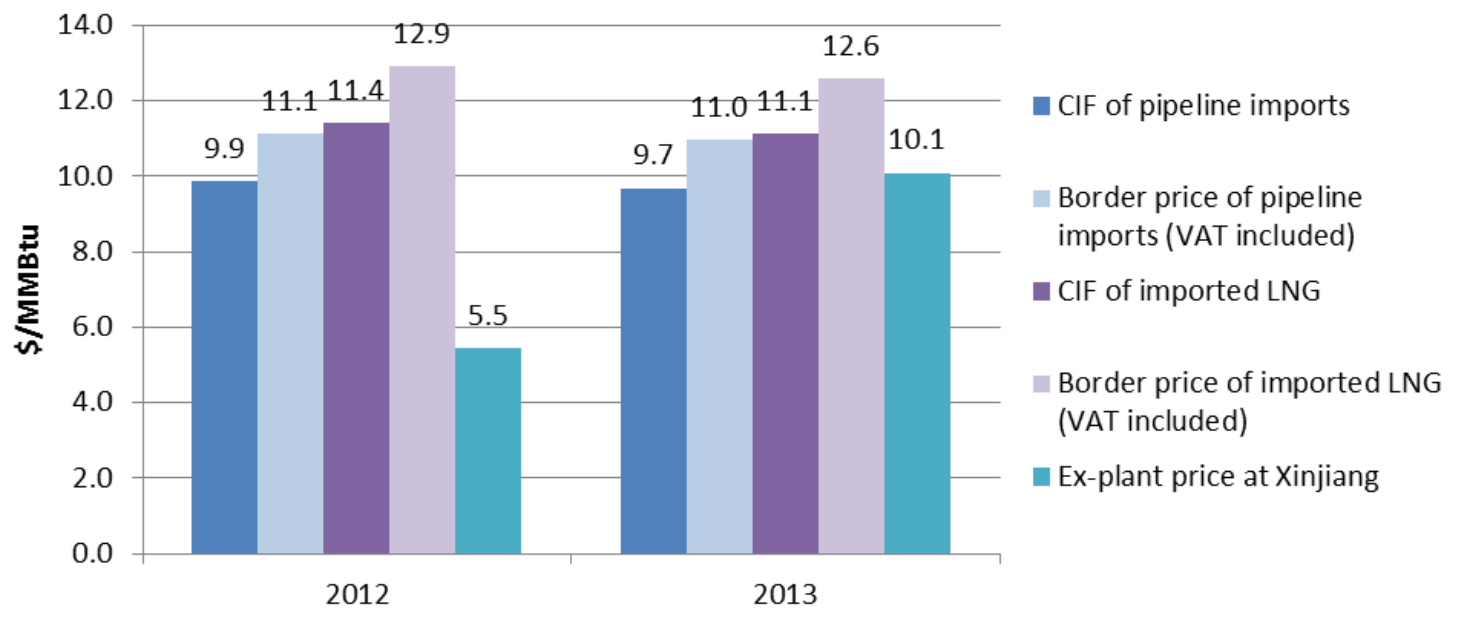

Figure 14. Border price vs ex-plant price 2012 \&2013. Data Source: import LNG \& pipeline gas prices (CNPC, 2014), ex-plant prices at Xinjiang (authors' estimates based on NDRC, 2010; NDRC, 2013). Prices are converted into $\$ / \mathrm{MMbtu}$ using the following conversion factors: $1000 \mathrm{~m}^{3}$ of natural gas $=35.7$

MMBtu (BP, 2014), $1 \$=6.16$ yuan (average exchange rate for 2014 from USForex, 2015). 

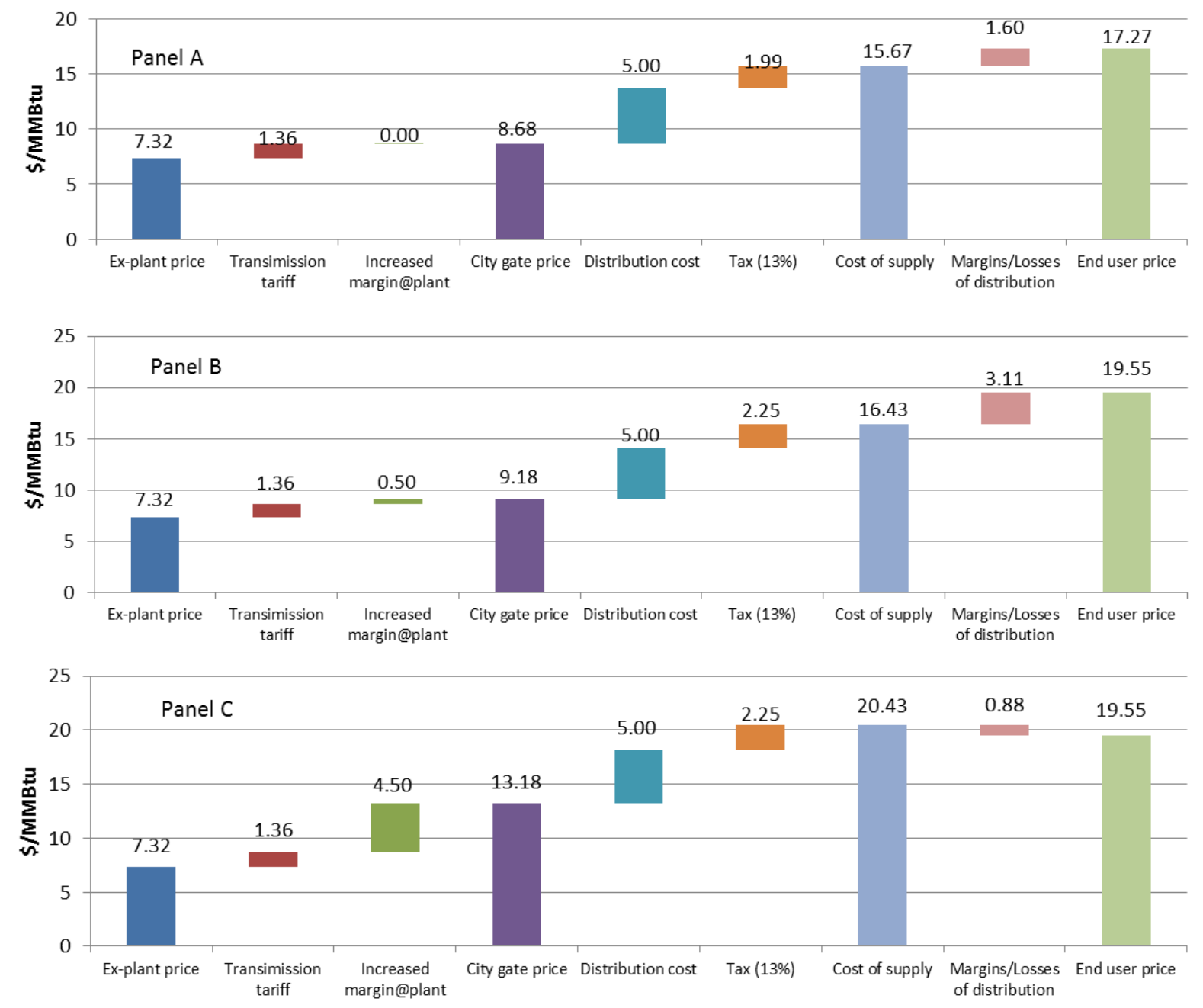

Figure 15. Margins of natural gas distributors in Harbin for non-residential use: (a) with old pricing; (b) with new pricing for existing volume; (c) with new pricing for incremental volume. Data source: Ex-plant prices (NDRC, 2010), City gate prices (NDRC, 2013), Distribution costs (Xinhua News, 2012), End user prices (Harbin Pricing Bureau, 2013), Transmission tariffs (authors' estimates based on personal communication with industry experts). 


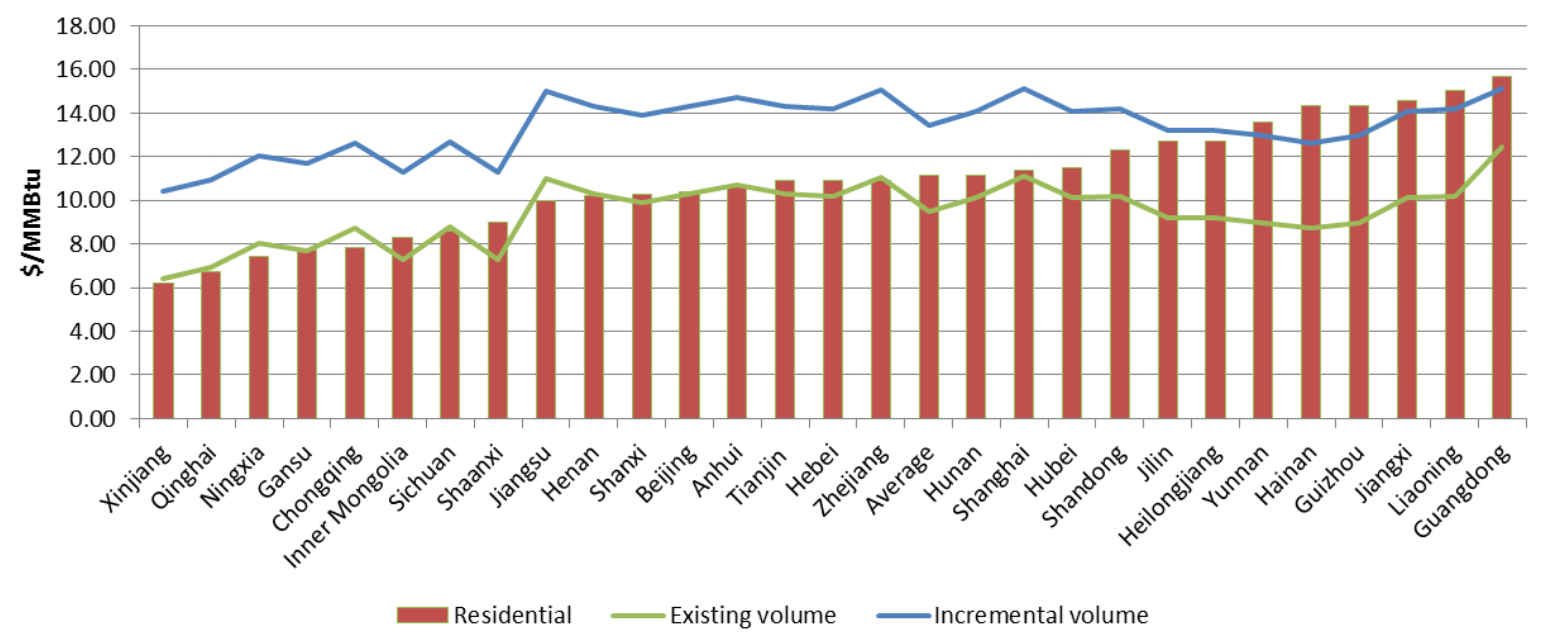

Figure 16. Natural gas prices for residential sector for the first adjustment period. Data Source: CNPC (2014), NDRC (2013).

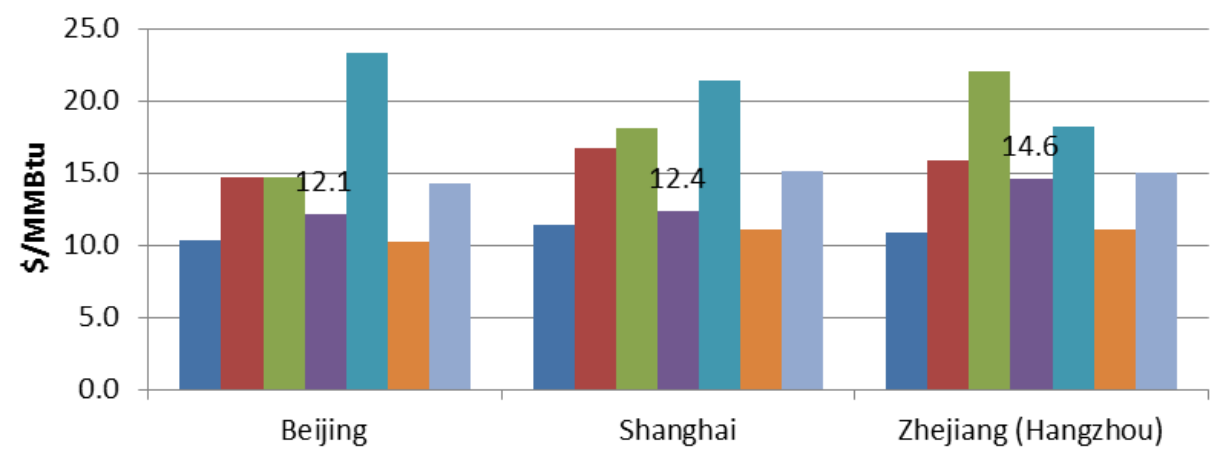

Residential
Public services
- Industry
Power sector
Transport
- City gate price, existing
- City gate price, incremental

Figure 17. End user gas prices in Beijing, Shanghai and Zhejiang in the first adjustment period. Data Source: CNPC (2014), NDRC (2013). 